\title{
The Effects of the Summer All Out Foot Patrol Initiative in New York City:
} A Difference-in-Differences Approach*

\author{
Forthcoming at Journal of Experimental Criminology
}

\author{
Thomas J. Bilach \\ New York City Police Department \\ New York City, NY \\ Sean Patrick Roche \\ School of Criminal Justice and Criminology \\ Texas State University \\ San Marcos, TX \\ Gregory J. Wawro \\ Department of Political Science \\ Columbia University \\ New York City, NY
}

\footnotetext{
*The views and opinions expressed in this manuscript are those of the authors, and do not necessarily reflect the official policies or positions of their employers.

Please direct all correspondence to Sean Patrick Roche, Texas State University, School of Criminal Justice and Criminology, Hines Academic Center 112, 601 University Drive, San Marcos, TX 78666 (email: sean.roche@txstate.edu).
} 


\section{The Effects of the Summer All Out Foot Patrol Initiative in New York City: A Difference-in-Differences Approach}

Objectives: The New York City Police Department's "Summer All Out" (SAO) initiative was a 90day, presence-based foot patrol program in a subset of the city's patrol jurisdictions.

Methods: We assessed the effectiveness of SAO initiative in reducing crime and gun violence using a difference-in-differences (DiD) approach.

Results: Results indicate the SAO initiative was only associated with significant reductions in specific property offenses, not violent crime rates. Foot patrols did not have a strong, isolating impact on violent street crime in 2014 or 2015. Deployments on foot across expansive geographies also has a weak, negligible influence on open-air shootings.

Conclusions: The findings suggest saturating jurisdictions with high-visibility foot patrols has little influence on street-level offending, with no anticipatory or persistent effects. Police departments should exercise caution in deploying foot patrols over large patrol jurisdictions.

\section{Keywords:}

Foot patrol; Policing; Deterrence; Difference-in-differences; New York City 


\section{Introduction}

For decades, police departments have deployed high-visibility foot patrols (Ratcliffe et al. 2011; Rosenbaum \& Lurigio 1994). There are several potential goals for such tactics: interpersonal reassurance of the general public, deterrence of would-be offenders, and a broader emphasis on standing as an emblem of public safety (Piza \& O'Hara 2014; Ratcliffe et al. 2011; Wakefield 2007). Foot patrols have often been characterized by practitioners and laypersons as a "proactive, non-threatening, community-oriented approach" (Wakefield 2007: 343). Yet, empirical evidence linking the influx of uniformed foot patrols to measurable reductions in crime and disorder is mixed and often weak (Ratcliffe et al. 2011). Still, foot patrol is often presumed by strategic planners in law enforcement agencies to be a useful application of police resources (Cowell \& Kringen 2016).

In the spring of 2014, gun violence escalated in several jurisdictions throughout the City of New York. In response, the New York City Police Department (NYPD) instituted its first iteration of the "Summer All Out" (SAO) initiative, a 90-day intervention that deployed approximately 300 additional uniformed officers to several precincts and police service areas (PSAs) during the summer months. High-visibility, saturation foot patrols comprised the bulk of their assignments during the intervention phase. These extra officers were drawn from administrative positions - located at police headquarters and other off-site locations - far removed from participating jurisdictions. Upon conclusion of the initiative, members returned to their original assignments.

The SAO initiative began shortly after the second appointment of William J. Bratton as Police Commissioner. Though crime has declined substantially across the United States since 
the mid-1990s, these declines were particularly steep in New York City (Baumer \& Wolff 2014; Zimring 2012; but cf., Krivo 2014), and Bratton had presided over much of this decline during his first tenure as Commissioner. Yet, prior to 2014, under Raymond W. Kelly, the NYPD had been broadly criticized for its overuse of formal legal sanctions (Eterno \& Silverman 2012), which intensified further following Floyd, et al. v. City of New York, et al. (2013), where a federal judge found the NYPD's widespread practice of "stop-and-frisk" constituted a policy of indirect racial profiling. Newly elected Mayor Bill de Blasio and newly appointed Commissioner Bratton sought to strike a tempered tone in policing inner-city communities. Thus, when reported gun violence pierced through many New York City neighborhoods in the spring of 2014, they sought a less intrusive approach than the classic police crackdown-the SAO initiative.

Police officials publicly announced the SAO initiative, giving explicit details to the mainstream media of the intervention's duration and the precise patrol jurisdictions where SAO officers would police on foot. The initiative was heralded as crucial to the city's ongoing violence-reduction strategy (see, e.g., Macedo et al. 2015). In the initial phase of the initiative, NYPD executives seized on the opportunity to report initial crime reductions - comparing monthly counts of reported crimes in a single intervention month with that same month in the previous year. Police officials continued to trumpet its seeming success after the program concluded that year, and it was reimplemented in successive years under the assumption it was a critical preemptive crime-prevention strategy.

At the same time, large-scale interventions of this kind-where many participating personnel are temporarily reassigned to special projects-can incur significant monetary costs. We estimate the SAO initiative costs the NYPD a minimum of $\$ 2$ million in overtime funding 
each year. Please note, this total only includes the compensatory requirement for SAO officers

to travel to and from their temporary assignments. It does not include costs associated with program design and officer retraining. ${ }^{1}$

Unfortunately, we are unaware of any internal police reports or peer-reviewed scientific research evaluating the impact of the SAO initiative on crime and violence. Further, though some early research (Eck \& Maguire 2006; Kelling et al. 1974; Manning 1977) suggested increases in the number of police on random patrol failed to have general deterrent effects, Nagin's (2013: 235) review of current research suggests there is a consistent and substantial general deterrent effect of increased police presence on serious crime (see also Nagin et al. 2015). Thus, the present study aims to evaluate the effects of the SAO initiative on reported crimes and shooting incidents in 2014 and 2015. From a theoretical standpoint, empirically evaluating the efficacy of saturation foot patrols provides evidence of the crime suppression benefits of officers serving a "sentinel-based" function (Nagin 2013; Nagin et al. 2015).

\section{Policing and General Deterrence}

Police interventions aimed at general deterrence, such as the SAO initiative, rest on two crucial hypotheses. First, would-be offenders should logically weigh the costs and benefits of their actions before committing crime (Beccaria 1963[1764]; Becker 1968; Zimring \& Hawkins

\footnotetext{
${ }^{1}$ Because this was not a permanent transfer, New York State labor laws would mandate remuneration for employees traveling to participate in this department-sponsored initiative. Contractually, participating officers were entitled to two hours and 30 minutes of "travel time" to travel to, and from, their temporary assignments. Monies granted for "travel time" are payable to NYPD officers at their regular hourly rate. Although incurred travel time is not calculated at a traditional overtime rate, it is still subject to normal overtime reporting protocols. The "travel time" rate for an NYPD officer with more than 5.5 years of service is $\$ 44.77$ per hour, which equates to approximately $\$ 112$ of overtime earnings per officer, per day. Assuming officers worked traditional 8-hour shifts with steady days off, we would expect a total of 60 work appearances during the intervention phase.
} 
1973). Second, the criminal justice system has the capacity to alter the cost/benefit calculations of would-be offenders via the threat of formal punishments (Nagin 2013; Nagin et al. 2015), particularly the likelihood of apprehension (Apel 2013; Pratt et al. 2006). This in turn can cause individuals to change their behavior, deterring them from future criminal actions (Cook 1980). Crucially, policy interventions cannot directly manipulate laypeople's subjective perceptions of sanction risk (Nagin 2013; Pickett \& Roche 2016). Instead, policy intervention can influence the objective risk of apprehension in certain areas and times (e.g., by putting police in field), with the hope that individuals' subjective perceptions will update accordingly. Deterrence is thus a theory of information and its transmission (Sherman 1990).

The SAO initiative was largely an exercise of police presence alone (see Kubrin et al. 2010; Ratcliffe et al. 2011). Unlike multifaceted "focused deterrence" programs (see Braga et al. 2018), there were no efforts to inform or incapacitate serious or chronic offenders (e.g., Braga et al. 2019; Corsaro \& Engel 2015). Instead, sharp surges in the number of uniformed police visible to the public were intended to lead to increases in the objective risk of being apprehended. In theory, the high visibility of foot patrol assignments would cause potential offenders to notice this change, and in turn cause them to update their subjective perceptions of the risk of apprehension and punishment. This would, in turn, lead to decreases in criminal activity (see Nixon \& Barnes 2018; Pogarsky \& Loughran 2016).

To do this, the SAO initiative relied on police officers to fulfill a "sentinel" role, using their presence to act as "capable guardians" of public spaces (see Cohen \& Felson 1979; Eck \& Weisburd 1995; Felson 1994, 1995) and thus discourage potential offenders from taking criminal action in the first place (Nagin 2013; Nagin et al. 2015). Some scholars have argued for 
a formal theory and typology of the effects police may have on criminal activity (Cullen \& Pratt 2016). Nevertheless, others have found it sufficient to argue the police are especially suited to a sentinel role, particularly in areas where criminal opportunities are abundant and there are few private or informal capable guardians (Nagin et al. 2015; Marvell \& Moody 1996). Indeed, the striking iconography of police officers (e.g., uniforms, badges, tactical equipment, etc.), and the direct risk they pose to would-be offenders as formal agents of social control, may have a far greater deterrent effect than any non-police agents or groups (Telep \& Hibdon 2018: 19; but, cf., Kleck \& Barnes 2014).

\section{Police Staffing}

Several informal and formal evaluations of the effects of precinct-level staffing surpluses on crime have been conducted over the last sixty years. One of the earliest occurred in New York City in $1954 .^{2}$ This NYPD program nearly doubled personnel assigned to the 25th Precinct in East Harlem for a period of four months (Wilson 2013). In 1966, a study sought to quantify the impact of a 40 percent increase in police manpower on precinct crime rates over an eightmonth period in New York City's 20th Precinct while staffing in other precincts remained constant. Though not ideal field experiments, these two programs suggested augmenting manpower in a specific precinct might yield short-term crime control benefits (Press 1971). In particular, the 1966 study found appreciable net reductions in average weekly crime-most

\footnotetext{
${ }^{2}$ The details of "Operation 25 " were found in a pamphlet published internally by the NYPD. Wilson (2013) offers a more in-depth appraisal of the program.
} 
notably among street offenses-between low- and high-manpower periods, over and above changes in control precincts that did not experience a staffing increase (Press 1971).

As crime rates sharply increased during the late 1960s and early 1970s, the Kansas City Preventive Patrol Experiment called into question the efficacy of random motorized patrols as a viable deterrence strategy (Kelling et al. 1974; but, cf., Sherman 2013). Following this, two experimental evaluations suggested changes in foot patrol did not yield appreciable crime control benefits (Bowers \& Hirsch 1987; Kelling et al. 1981). The first, as part of New Jersey's Safe and Clean Neighborhood Act, involved the City of Newark implementing a broad foot patrol experiment (Kelling et al. 1981). The study assessed the impact of varying the dose of foot patrols across twelve experimental beats. Results indicate crime rates, as indicated by both police data and victimization surveys, were unaffected across the treatment beats. Although, consistent with the public relations focus of neighborhood foot patrols, a later analysis found reductions in community members' fear of crime (Pate 1986).

The second, in 1983, focused on the Boston Police Department's implementation of a program that shifted officers away from random motorized response to foot patrols (Bowers \& Hirsch 1987). These foot patrols were not found to be associated with reductions in citizen calls for service or reported crimes. Still, other studies have found modest support for foot patrols as a viable deterrence strategy. Beginning in 1978, the police department of Flint, Michigan coproduced a grassroots foot patrol program with community stakeholders (Trojanowicz \& Baldwin 1982). Net reductions in reported offenses were observed in ten of the 14 experimental beats. ${ }^{3}$ Additional benefits were observed with respect to calls for service, which

\footnotetext{
${ }^{3}$ Crime remained unchanged in one experimental beat.
} 
fell by nearly half between these two time periods. Nevertheless, it should be noted many older evaluations were limited by issues of both measurement and statistics, such as the selection of inappropriate treatment areas (Ratcliffe et al. 2011; Sherman \& Weisburd 1995).

Fortunately, there have also been more recent foot patrol interventions in major American cities. A randomized control trial of police foot patrols in Philadelphia circa summer 2009 found a significant reduction in violent crime after 12 weeks (Ratcliffe et al. 2011). Assessments of Newark's 2008-2009 Project Impact initiative (Piza 2018; Piza \& O’Hara 2014), which combined both proactive "enforcement actions" and more sentinel-like "guardian actions" of foot patrols, also yielded generally positive results. Piza and O'Hara's (2014) results indicate total street violence was reduced. Further, incidents of murder, shootings, and nondomestic aggravated assault also decreased within the experimental area, with little evidence of displacement to other areas. Piza (2018) later found guardian actions in particular, such as business and bus checks as well as citizen contacts, conducted by foot patrol officers were associated with a decreased likelihood of robberies and overall violence.

Over time, the geographic distribution of crime has become a primary focus of researchers and practitioners seeking to understand the relationship between place-based strategies and crime (see Weisburd 2015; Telep \& Weisburd 2018). Rather than deploying officers randomly or widely on foot or motorized vehicles, these recent policing strategies concentrated their efforts on specific places responsible for a large proportion of crime (see Braga et al. 2018). Deterrence at micro-places, or "hot spots," is now well-established in the criminological literature (Braga \& Bond 2008; Novak et al. 2016; Sherman et al. 1989). Much of this is the result of successful researcher-practitioner co-production, allowing for more robust 
experimental evaluations of place-based policing strategies. For instance, recent reviews of a large body of quasi-experimental and experimental studies of hot spots policing interventions suggest these strategies can provide statistically significant, albeit somewhat modest, reductions in crime (Braga et al. 2012, 2014; National Research Council 2004). Moreover, it seems unlikely these crime reductions were attributable only to displacement to adjacent areas (see Weisburd et al. 2006).

In the hot spots literature, the size of treatment areas and the tactics employed at those areas can vary significantly (cf., Sherman \& Weisburd 1995; Chainey \& Ratcliffe 2005). Still, while hot spots studies constitute a crucial adjacent literature with relevance to focused deterrence policing strategies, the SAO initiative, which the current study assesses, is not itself a hot spots policing intervention. First, while prospective hot spot areas do vary in size, the SAO's treatment units of entire New York City precincts are likely too large to fall under the classic conceptualization of a hot spot (Chainey \& Ratcliffe 2005; Sherman \& Weisburd 1995). Second, the SAO initiative was only a surge of sworn officers. It did not involve elements of problem-oriented policing, and thus bears little resemblance to hot spots interventions that analyze local problems to craft particular responses within problem areas (e.g., Braga et al. 2019; Telep \& Hibdon 2018). Thus, the SAO is better considered a more traditional foot patrol surge, an "unfocused community policing strategy with only weak-to-moderate evidence of effectiveness in reducing fear of crime" (Ratcliffe et al. 2011: 797; see also, National Research Council 2004). Nevertheless, some reviews of research suggest even unfocused policing activity can reduce criminal activity (Kubrin et al. 2010; Sampson \& Cohen 1988; Wilson \& Boland 1978). The current study assesses whether this holds for the SAO initiative. 


\section{Evaluation Design}

\section{Study Setting}

Our study setting is the City of New York, the most populous city in the United States, home to approximately 8.5 million residents, more than a third of which are foreign-born. The city spans a geographic area of 302 square miles and encompasses five boroughs, which vary significantly in size and demographic composition. As a unique metropolitan environment with a heterogenous population, local law enforcement must adapt to a multifaceted collection of demands voiced by community residents.

\section{The New York City Police Department}

The New York City Police Department (NYPD) is the largest municipal police department in the country, employing approximately 36,000 full-time sworn officers-more than twice as many officers as the second largest police department in the United States. Their members perform a wide variety of law enforcement functions related to public safety and security, counterterrorism, and emergency management. Our evaluation research is concerned principally with the NYPD's Patrol Services Bureau (PSB), its largest operational bureau. Presently, PSB is divided into eight patrol boroughs, which are further subdivided into 77 police precincts. Though not perfectly precise, demarcated precinct borders comport reasonably well with the boundaries of established neighborhoods. The "precinct" jurisdiction is the primary aerial unit of observation.

\section{The "Summer All Out" Initiative}


The present evaluation research is focused on the 2014 and 2015 iterations of the "Summer All Out" (SAO) initiative. Police officials designed the initiatives with the express purpose of augmenting the visible display of uniformed officers on foot within a subset of precinct jurisdictions. On average, the geographic area of a typical precinct jurisdiction is 3.8 square miles. Residential precinct population varies widely, but a typical precinct ranges from 70,000 to 150,000 residents. Each participating SAO precinct received a contingent of approximately 20 SAO officers, on average. ${ }^{4}$ This would net a typical SAO jurisdiction with four to five additional officers on visible foot patrol per square mile during deployment hours, which is the equivalent to the addition of two uniformed officers per 10,000 precinct residents. ${ }^{5}$ Precinct staffing remained constant during the intervention phase; the SAO surplus was intended to supplement the precinct's current patrol strength. Please note, when set against the background of typical American law enforcement operations, the SAO deployment was colossal. The NYPD's subset of "surplus" foot patrol reinforcements, which represents only $1 \%$ of their total patrol contingent, exceeds the entire headcount of most law enforcement agencies in the United States, where three-quarters of all local police departments employ a total of thirty full-time sworn officers or less (Reaves 2015).

\footnotetext{
${ }^{4}$ The NYPD does not publish their staffing metrics. We only received aggregated summary statistics of deployed SAO personnel.

${ }^{5}$ Because precinct commanders were given discretion in their deployment of SAO officers, the spatial reach of each precinct's SAO contingent within precincts is largely unknown. It is unlikely that deployment of foot patrols was intended to evenly saturate the precinct aerial unit. Despite this, the distribution of SAO officers was widespread enough to warrant the designation of the precinct jurisdiction as the primary unit of analysis.
} 
Precinct commanders deployed personnel on foot and were given latitude regarding deployment zones and scheduling. ${ }^{6}$ The magnitude of mobilized guardianship onto public street segments was not trivial, even if dispersed across rather large aerial units. Most precinct commanders deployed SAO officers on two semi-overlapping shifts to ensure coverage during the late evening and early morning hours. In general, NYPD patrol duty scheduling is organized into three 8-hour shifts; each shift is comprised of three squads, only two of which are present for duty on a given shift. Two "squads" are comprised of, on average, 26 to 32 officers. Thus, the average SAO contingent was a near 70 percent increase in patrol strength during peak crime hours.

SAO officers were instructed to maintain their visibility in shared public spaces and to exercise their "professional presence" whenever necessary. Members were not encouraged to initiate formal interactions with members of the public. Citywide enforcement contacts (e.g., arrests, summonses, Terry stops, etc.) declined monotonically throughout our observation period. In particular, "stop-and-frisk" reporting decreased three-quarters in 2014 compared with the previous year. Disengagement persisted again in 2015 , where stop activity was half that of its previous year's output. ${ }^{7}$ Reductions were particularly pronounced in participating SAO jurisdictions - a trend that persisted during the intervention phase. Among the jurisdictions selected in 2014, stop reporting was 12 percent lower during the intervention phase when

\footnotetext{
${ }^{6}$ Anecdotal evidence gleaned from interviews with participating officers indicates that many policed street segments on foot-alone. In general, the diffuse dispersal of individual foot patrol units improved the spatial reach of SAO officers within precincts.

${ }^{7}$ The magnitude of disengagement cannot be overstated. In 2014, the NYPD initiated approximately 150,000 fewer stops of individuals suspected of criminality than in the previous year. Data is publicly accessible on the following webpage: https://www1.nyc.gov/site/nypd/stats/reports-analysis/stopfrisk.page
} 
compared with the previous 90 -day period. A similar pattern emerged in 2015 , where the average stop output of a typical SAO jurisdiction during intervention months was one-fourth that produced in the previous 90-day period. The decline in Terry stops, even among the city's high-crime jurisdictions was curious. In the years preceding the SAO initiative, NYPD officers heavily invoked this legally sanctioned practice to routinely intervene with suspected criminals in public domains. ${ }^{8}$

Further, SAO officers' sustained presence on foot in relative isolation rendered them mostly unavailable to field calls for police service (cf., Wood et al. 2014). It is tactically unsafe to respond to emergency 9-1-1 service requests, unassisted, while on foot. Internal policy indicates the NYPD typically deploys "two-officer" motorized police vehicles to perform patrolrelated duties. It is rare to observe uniformed police resources responding to service requests unaided.

It is also worth highlighting that many SAO officers were previously assigned to relatively coveted administrative positions. A large proportion of the selected officer contingent were seasoned members and perhaps less likely to exhibit a crime-fighting orientation. Prior research has demonstrated that a penchant toward crime-fighting begins to wane after five years of service (Brown 1988). Moreover, walking a police beat has been widely regarded as more difficult than standard vehicular patrol, and more traditionally viewed as form of punishment (Wilson \& Kelling 1982). Once the intervention concluded, the mainstream media

\footnotetext{
${ }^{8}$ The federal monitor's reports on police stops in New York City suggests a widespread practice of underreporting. Some estimates suggest nearly half of all stops remain undocumented. In spite of the monitor's findings, the sharp reduction in street stops following Floyd is still noteworthy, even if it may be an overestimate. Access to the monitor's semi-annual reports can be found here: http://nypdmonitor.org/monitor-reports/
} 
received chronicles of discontentment among the senior rank-and-file; displeased with their reassignment to foot patrol, some SAO officers attempted to evade deployment by feigning injury or filing for early retirement. ${ }^{9}$

In light of our understanding of the SAO blueprint, the present paper offers an exclusive assessment of the swift intensification of visible guardianship in a subset of sanctioned patrol jurisdictions. The SAO model's strict sentinel-focus is most consistent with a "watchman" style of policing, whereby the principal function of the officer is the maintenance of order (Wilson 1968). As noted earlier, the timing of the initiative coincided with unprecedented levels of formal disengagement with the community.

The first iteration of the SAO initiative began on July 7th, 2014 and concluded on October 4th, 2014. Nearly 300 uniformed officers were reassigned from administrative positions and apportioned to ten participating precincts for the 90 -day intervention phase ${ }^{10} \mathrm{At}$ the conclusion of the SAO initiative, the additional officers were pulled back and returned to their previous assignments. Except for the 113th Precinct in Queens, all precincts were located in Brooklyn or the Bronx.

The second iteration of SAO initiative commenced on June 6th, 2015 and concluded on September 5th, 2015. Again, the department reassigned nearly 300 uniformed officers to ten

\footnotetext{
${ }^{9}$ https://www.nydailynews.com/new-york/nypd-summer-article-1.1968357

${ }^{10}$ The SAO initiative was also designed to combat crime occurring in Police Service Areas (PSAs). Officers assigned to PSAs patrol New York City Housing Authority (NYCHA) facilities and grounds. Because NYCHA properties are scattered throughout the City of New York, some PSA boundaries span several precincts. Many NYCHA developments are nested within precinct jurisdictions subjected to the initiative, though jurisdictional responsibility lies with the PSA. Officers assigned to precincts typically police all areas within precinct boundaries except NYCHA property. Some SAO officers were deployed to saturate PSA jurisdictions via foot patrols. Because the units of analysis are large and we did not know a priori the deployment strategy of PSA officers, we do not compare PSA crime to precinct crime.
} 
participating precincts for the 90-day intervention phase. With the exception of the 120th

Precinct in Staten Island, all were again located in Brooklyn or the Bronx. Figure 1 shows the precincts that received the intervention in 2014 and 2015, seven of which received the intervention in both years.

\section{[Figure 1 about here]}

\section{Analytic Framework}

Reviews of weekly CompStat reports suggest department executives chose precincts for the SAO initiative on the basis of their high count of total reported shooting incidents. To minimize potential selection bias associated with program implementation, models were estimated using a difference-in-differences (DiD) framework. Under this specification, changes in monthly crime rates and monthly shooting counts for precincts subjected to the intervention were compared with the changes in non-participating precincts where the intervention was absent. Precinct jurisdictions selected to implement foot patrols for the 90-day treatment phase serve as our treatment group.

While SAO precincts were typically densely populated territories with disproportionately high crime rates, these treated precincts were not the only areas experiencing a surge in violence during the summer months of 2014 and 2015. Other areas of the city, most particularly the northern sections of Manhattan and southern sections of Queens also exhibited elevated rates of crime and a high concentration of gun violence, but were never subjected to the program. ${ }^{11}$ Other non-participating jurisdictions with comparable crime and disorder concerns

\footnotetext{
${ }^{11}$ NYPD officials did not explicitly disclose their selection criteria for participating jurisdictions. The composition of the treatment group suggests indicators of violence were considered, which are often weighted by other precinct characteristics such population size and density. Many of the NYPD's 77 precinct jurisdictions never received a
} 
were also located in geographically proximate regions of the city, such as within the same borough. Thus, we designated all non-program precincts as our control group. ${ }^{12}$

One of the principal identifying assumptions of the DiD estimation strategy is the visual exhibition of parallel group trends prior to treatment (Blundell \& MaCurdy 1999; Meyer 1995). Put differently, the design assumes trends in outcomes between treatment and control groups would move in tandem in the absence of program exposure (Gertler et al. 2016). Trend equivalence before a policy change is often implicitly assumed, yet the visual observation of any parallelism, or divergence, in trend is amenable to explicit empirical testing should serial observations of crime outcomes exist prior to treatment. ${ }^{13}$ Most of New York City's major crime indices, in general, exhibit low volatility over time across treatment and control jurisdictions. ${ }^{14}$

\footnotetext{
summer contingent surplus guardianship. Other regions of the city with similarly pressing crime and disorder concerns were not included; this is due, in part, to the limited availability of personnel to saturate all jurisdictions equally. This supports, to a certain degree, the "randomness" of precinct selection.

12 Four precincts were excluded from the control group. The Central Park Precinct is an expansive recreational environment without an official residential population. Victims of crime are representative of the ambient population visiting the park, which precludes any accurate assessment of per capita crime rates. Likewise, the $14^{\text {th }}$ and $18^{\text {th }}$ Precincts in midtown Manhattan typically have large ambient populations far surpassing their residential populations. The $121^{\text {st }}$ Precinct in Staten Island was summarily excluded because this area was not officially recognized as a precinct jurisdiction until the summer of 2013.

${ }^{13}$ Empirical testing of common group trends is akin to a placebo treatment procedure whereby crime outcomes are regressed on interactions between a treatment indicator and a full series of $T-1$ dummies for months (St. Clair \& Cook 2015). Coefficients on the interaction terms represent the conditional outcome distribution over time. Statistically significant differences should only arise when the treatment group enters into the treatment condition. Alternatively, one could test for nonequivalence of the group-level trends using only pre-intervention outcomes (Ryan 2009). In either setting, the pre-period coefficients associated with several of New York City's major crime indices were indistinguishable from zero, supporting the assumption of trend equivalence.

${ }^{14}$ As New York City's major crime indices drop to historic lows, differences in crime rates across time show greater volatility-in percentages - than in their actual counts. CompStat evaluations typically compare counts of crimes in one jurisdiction with itself in the previous year. Even meager differences over time in aggregate offense counts, if small, can produce large percentage changes. We contend that police officials might overestimate the severity of even a modest crime spike. Baseline deviations in crime are not likely to persist, or be demonstrative of a significant historical divergence in trend.
} 
Figure 2 depicts monthly trends in New York City's violent and property crime indices, separately, by year. ${ }^{15}$ We juxtaposed SAO adopters with all citywide jurisdictions in the months surrounding the exposure period. Shaded regions highlight the 90-day intervention phase in both years. As indicated in Figure 1, a discrete subset of jurisdictions were treated across years, though many previously treated precincts received the intervention more than once. Each trend line represents the unique evolution SAO and non-SAO adopters in each treatment year.

\section{[Figure 2 about here]}

Comparing the unconditional evolution of mean per capita crime trends between SAO and non-SAO jurisdictions aids the assessment of parallel trends before the foot patrol surge. Pre-treatment crime trends exhibit a visual stability before the onset of SAO guardianship; month-to-month volatility is relatively low pre-intervention. Program exposure appears to induce a transitory deviation from this common pre-treatment trend. Surprisingly, average violent crime rates in program precincts deviate upward in the two months postimplementation of the 2015 SAO initiative.

\section{Data}

Crime data were obtained from the NYPD's crime data warehouse via their open data portal. The full dataset consists of the population of felony and misdemeanor crime complaints ( $n=2,134,067$ ) between 2012 and 2016. We also secured, separately, the population of

\footnotetext{
${ }^{15}$ Violent crime is a composite index comprising murder/non-negligent manslaughter, rape, robbery, and felonious assault. Later, we disaggregate composite measures to examine the effect of the SAO initiative on specific crime types.
} 
shooting incidents $(n=5,783)$ for the same period. ${ }^{16} A$ "shooting incident" as defined by the NYPD is an adversarial exchange resulting in at least one person being wounded by a fired bullet. These incidents are not merged with the felony and misdemeanor data in order to calculate a traditional crime rate.

Note, shooting incidents are crimes in and of themselves, representing acts of felonious assault or manslaughter, though they may be a consequence of the commission of other violent crimes. Thus, in order to avoid double counting, we model shooting incidents separately as a Poisson process. Shooting incidents may also be a reliable barometer of the violence occurring within a jurisdiction. These events are difficult to underreport should victims require hospital treatment. ${ }^{17}$ In addition, a substantial proportion of shooting incidents occur in visible public spaces. Our data suggests shooting incidents are not randomly distributed about the city. Their incidence is typically clustered in neighborhoods already fraught with crime.

We proceeded by winnowing the available pool of offenses to only crimes likely to be influenced by the widespread distribution of foot patrols in public spaces. First, we kept only those offenses where the local precinct was listed as the investigative authority. Second, we restricted attention to "street" offenses. One-third of either felonious or misdemeanor crimes investigated by the local precinct occur on visible street segments immediately navigable by uniformed patrolmen. In half of all "street" crimes, officers also specified a "Location Type" for the reported offense. Of those, 9 out of 10 reported street-level crimes occurred either "in

\footnotetext{
${ }^{16}$ The data that support the findings of this study are available from the NYC OpenData portal, (https://data.cityofnewyork.us/Public-Safety/NYC-crime/qb7u-rbmr), are available from the authors upon request. ${ }_{17}$ Hospital physicians and superintendents are mandated to report bullet wounds to police authorities, and any failure to do so is a class " $A$ " misdemeanor according to the New York State Penal Law (see, e.g., § 265.25).
} 
front of" or "opposite of" the incident location. Our selection criteria reduced the pool offenses to 698,222 crimes available for analysis. Official crime reports were aggregated by month and normalized by the residential precinct population size.

The shooting data is similarly restricted to those incidents occurring in public domains. Gun violence within city limits generally materializes in shared, communal public spaces where residents can freely travel. Of all precinct shootings observed over the 5-year period, 7 out of 10 occurred in open-air settings. Our selection criteria reduced the pool of incidents to 4,012 shootings available for analysis. ${ }^{18}$ Aggregated events thus represent the total monthly count of open-air shooting incidents reported by the police.

\section{Models for Crime Indices}

The NYPD monitors their major crime indices by comparing jurisdictions with themselves in the previous year. Put differently, for any precinct and year, the epoch under evaluation (e.g., 28-day cycle) is typically matched with its counter-epoch in the preceding year. Impact evaluations in this context can thus be achieved using month-to-month comparisons of crime counts (e.g., comparing violent crime in July-2013 with July-2014). In essence, precincts serve as controls for themselves.

The shortcomings of this evaluation approach are apparent. Index crime, in general, has been trending downward since the mid 1990s. ${ }^{19}$ If counterfactuals are not temporally aligned,

\footnotetext{
${ }^{18}$ The NYPD's shooting database did not record any incident-level data for three jurisdictions over the 60-month observation period. The $17^{\text {th }}, 19^{\text {th }}$, and $111^{\text {th }}$ Precincts did not report any open-air shooting incidents during our window of observation; these were removed from our group of controls.

19 Index crime is comprised of "seven major" crime types: murder/non-negligent manslaughter, rape, robbery, assault, burglary, grand larceny, and grand larceny auto. These crimes are regularly tracked and monitored as part of the NYPD's CompStat system.
} 
then average differences in index crime between jurisdictions exposed and unexposed to treatments could be due to longstanding maturational trends in New York City's major crime indices. Thus, any net reduction in index crime counts could be due to secular declines in crime over the last two decades.

To overcome these concerns, we used a DiD approach to estimate the impact of the SAO initiative on logged monthly crime rates. ${ }^{20}$ The effects of SAO exposure on crime rates were estimates via least-squares. Model 1 takes the form of the classical DiD specification:

$$
\log \left(y_{p t}\right)=\alpha+\gamma \text { Treat }_{p}+\lambda \text { Post }_{t}+\delta\left(\text { Treat }_{p} \times \text { Post }_{t}\right)+\theta X_{p t}+\varepsilon_{p t}
$$

where the left-hand side denotes the logged per capita crime rate for precincts $p$ in months $t$. The variable Treat $_{p}$ is a group-level indicator equal to unity if precinct $p$ was selected into the treatment group, 0 otherwise. Standardized treatment months are represented by the time dummy Post ${ }_{t}$, indexing post-treatment months in both treatment and control groups.

In the 2014 SAO initiative, post-treatment months were July, August, and September; only the six months pre-treatment were compared with the three months post-treatment. In the 2015 iteration, post-treatment months were June, July, and August; accordingly, we only compared the five months pre-treatment with the three months post-treatment. Months beyond conclusion of each iteration were ignored. Interacting the group and time indicators gives us an estimate of $\delta$, the treatment effect for precincts $p$ that received the surplus manpower during treatment months $t$. The variable $X$ denotes precinct-level controls. ${ }^{21}$

\footnotetext{
${ }^{20}$ In all instances, $\log ($.$) denotes the natural logarithm. The absence of crime reports in any particular month is$ imputed with a value of 1 to facilitate this transformation.

${ }^{21}$ Note, we adjust for obvious controls such as population and area, even though they do not assist with the identification of our causal parameter of interest. If any observed precinct characteristics do change across time, they change slowly. For example, the $121^{\text {st }}$ Precinct is Staten Island was not officially recognized as a precinct jurisdiction until late 2013 . The $121^{\text {st }}$ Precinct absorbed sector boundaries within neighboring precincts to alleviate
} 
Model 1 isolates the impact of the SAO initiative on crime by estimating separate DiD models in only those years when the intervention was in effect; this may be insufficient for two reasons. First, we assume the initiative has an immediate and constant impact on crime with no further effects; this assumption may be impractical. Instead, program effects may grow and/or decay in treatment withdrawal periods. Second, we assume precinct selection was independent of pre-existing crime trends. When subsets of patrol jurisdictions receive interventions on the basis of a transitory spike in violence, then earlier models could potentially overstate effects should crime revert to pre-program levels in the post-period. To overcome these concerns, we estimate a second equation that explicitly models the movement of crime before and after each 90-day treatment window. Pooling years 2012 to 2016 together accounts for all iterations of the SAO initiative in one equation. The 5-year panel results in over 60 'month-year' observations. Model 2 is a "generalized" DiD equation adapted from Bertrand et al. (2004) and is estimated via least squares:

$$
\log \left(y_{p, t}\right)=\varphi_{p}+\omega_{t}+\sum_{j=-2}^{1} \delta_{j} S A O_{p, t+j}+\varepsilon_{p t}
$$

where $\varphi_{p}$ and $\omega_{t}$ are fixed effects for precincts and months, respectively. Estimation of the right-hand side fixed effects was achieved using a series of $P-1$ indicators for precincts and $T-1$ indicators for months. Treating precinct- and month-specific effects as parameters to be estimated is algebraically equivalent to estimation in deviations from means (Angrist \& Pischke,

their workload. In general, the inclusion of precinct-level controls does not appreciably influence our results. In fact, double-differencing in this context produces results similar to the standard fixed effects estimator, and so our models will silently exclude many time-invariant controls once we allow for the estimation of precinct- and timespecific intercepts. Also, our equations are insensitive to the inclusion of precinct population weights. 
2009). The "generalized" DiD model is a two-way fixed effects estimator and is amendable to settings with intermittent program exposure over time. Precinct fixed effects control for unobserved time-invariant precinct-level heterogeneity; month fixed effects account for common temporal shocks, absent the SAO intervention, affecting all precincts. Such a model systematically accounts for any omitted cofounders that are fixed over time and across precincts.

The treatment variable $S A O_{p t}$ represents our interaction term from earlier (i.e., Treat $_{p} \times$ Post $\left._{t}\right)$. Since the post-period is not standardized across years and a different subset of jurisdictions were treated in each iteration of the program, then our policy indicator must be instantiated manually to account for this interaction. Thus, $S A O_{p t}$ is a treatment dummy equal to unity if a precinct was in the treatment group (i.e., either 2014 or 2015 -or both) and in a post-treatment period, 0 otherwise. $S A O_{p t}$ does not demarcate a specific treatment group; rather, it is discrete indicator for program precincts during program months. Such a policy indicator can thus switch on and off depending on the intervention phase, and offers a more flexible modeling strategy than the classical DiD model. Two iterations of the SAO initiative were instituted and removed over the 60 -month observation period. Merging all years together allows us to account for more of the systematic variation in crime outcomes over time.

Note, this model is not restricted to assessing static treatment effects. In fact, the righthand side summation parsimoniously specifies the estimation of static and time-varying treatment effects. Each $\delta$ is subscripted to index the $j$-th additive treatment effect, such that $-2 \leq j \leq 1$, inclusive of 0 . We estimate one lead and two lags of the SAO policy variable. Notice, as we increment along this summation interval, we adjust the full time configuration by 
j. Our lead parameter (i.e., $\delta_{1}$ ) estimates an anticipatory effect (see Smith et al. 2002); lagged parameters (i.e., $\delta_{-2}, \delta_{-1}$ ) estimate persistent effects. Our static parameter $\delta$ (i.e., $\delta_{0}$ ) is still our causal estimand of interest and captures the immediate effect of treatment.

DiD assumptions would imply that $\delta_{j}=0 \forall j>0$. Consistent with a Granger causality test, future $S A O_{p t}$ should not predict $y_{p, t}$ (Granger 1969). Put differently, consequences should not precede causes (Angrist \& Pischke 2009). In our setting, however, we may observe general deterrent effects preceding program exposure. To illustrate, macro-level changes in police presence are often determined at the top of the NYPD administration, and large personnel deployments typically accompany of a formal announcement of the initiative's purpose. Press releases surfaced approximately one month prior to the commencement of the SAO initiative. Substituting $S A O_{p, t+1}$ into the full model will help capture any anticipatory behavior within program precincts in the month immediately before SAO adoption.

Assessing possible anticipatory effects is of substantive interest when program implementation involves a time gap between its announcement and ultimate effective date (Wing et al. 2018). Preemptive crime-suppression benefits may be a consequence of the early reporting of each initiative's start date..$^{22}$ However, a "zero-bounded" coefficient on a leading treatment variable has its methodological benefits. Failing to observe emerging ex ante changes in our outcome before the onset of the intervention supports claims of common trends before the surge in street-level guardianship. Moreover, estimates of $\delta_{j}, j \leq 0$ may persist or

\footnotetext{
22 Perhaps one could delineate a theoretical framework for a surge in violence in response to the imminence of the intervention. If public announcements are perceived early, it signals to offenders the "absence" of formal guardianship in public spaces in the weeks before the onset of foot patrol deployments.
} 
deteriorate with the passing of the initiative. Our goal of lagging the SAO treatment dummy is to investigate potential lasting effects once the initiative concludes. The first and second lag captures any "carry-over" effects in the months beyond program termination.

Our decision to express potential outcomes as a function of time-varying treatments, e.g., $y_{p t}\left(S A O_{p, t+1}, S A O_{p t}, \ldots, S A O_{p, t-2}\right)$ was not arbitrary. Applied researchers typically substitute "future" or "past" versions of a discrete treatment variable into their specification. ${ }^{23}$ Still, our approach may be insufficient to identify the dynamics of treatment throughout each transient SAO exposure phase. Later, we will fully explore the relevant time dependencies by interacting a year-specific treatment indicator with period (i.e., month) dummies specific to SAO and non-SAO jurisdictions.

Robust variance-covariance estimators were used for all models employing a DiD estimation strategy. One-way "precinct-level" cluster robust standard errors were estimated for all classical DiD models with two groups and two discrete time periods. ${ }^{24}$ However, in the more general DiD setting, we double cluster on precincts and months (Cameron et al. 2011; Petersen 2008; Thompson 2011). Double clustering along the cross-sectional and longitudinal dimension

\footnotetext{
${ }^{23}$ Our review of the DiD literature suggests there is no clear consensus regarding the optimal lead-lag structure. DiD studies investigating anticipatory effects often assess anywhere from one-to-three lead effects before treatment exposure (e.g., Autor 2003; Cavalcanti et al. 2019; Green et al. 2014; Grinols \& Mustard 2006; MacDonald et al. 2016). It is also not uncommon to find DiD evaluations report lead effects more than three periods before program/policy adoption (Azoulay et al. 2019; Venkataramani et al. 2019). In other settings, anticipatory effects are largely ignored and the authors only incorporate a static intervention dummy (Braga et al. 2018; Larsen et al. 2015).

${ }^{24}$ The classic DiD framework with two groups and a standardized time index for post-treatment months could only be estimated separately by year. One-way cluster robust standard errors, clustering on precinct, are less conservative than least-squares estimates assuming independent and identically distributed errors. We also estimated nonparametric variance-covariance matrices adopted by Driscoll and Kraay (1998), which are amendable to settings with dependence across cross-sectional units. This alternative uncertainty estimator is not appreciably different than standard 'sandwich' estimators that cluster on precinct.
} 
accounts for within-cluster dependence and is amenable to settings with geographic-based spatial correlation.

\section{Models for Shooting Incidents}

The NYPD tracks shooting incidents separately from its major crime indices; this is partly due to their severity. We view shooting incidents as a crucial outcome of interest since it appears the NYPD administration used this metric as a criterion for precinct selection. The low cardinality of shooting events across time and space does not lend itself to estimation via least squares. Poisson regression models were used to estimate the effect of the SAO initiative on shooting outcomes, which we modeled separately from the NYPD's major crime indices. The following two specifications proceed in a similar fashion and only apply to the shooting data. First, we model the immediate pre- and post-treatment months, separately, by year. We then follow with the "generalized" DiD approach which estimates all iterations of the SAO initiative in one equation.

Shooting outcomes show more volatility across time than the NYPD's standard crime metrics. To proceed, we explicitly sought to model trend divergence in monthly shootings across treatment and control jurisdictions. Model 3 is an adaptation of the classical DiD specification adjusting for calendar effects in the months before the onset of each SAO initiative:

$$
\begin{aligned}
\log \left(y_{p t}\right)=\alpha & +\gamma \text { Treat }_{p}+\sum_{\iota=-k}^{-1} \eta_{\iota} \text { Pre }_{t}^{\iota}+\lambda \text { Post }_{t}+\sum_{\iota=-k}^{-1} \rho_{\iota}\left(\text { Treat }_{p} \times \text { Pre }_{t}^{\iota}\right) \\
& +\delta\left(\text { Treat }_{p} \times \text { Post }_{t}\right)+\theta X_{p t}+\log \left[\frac{n}{10,000}\right]
\end{aligned}
$$


where the variable $\operatorname{Pr} e_{t}^{\iota}$ denotes a series of pre-intervention period dummies for each individual calendar month preceding program exposure (Ryan et al. 2015; St. Clair \& Cook 2015). Each estimate of $\eta_{\iota}$ represents the individual additive effects of disjoint time periods relative to the intervention, such that $-k \leq t \leq-1$. Each estimate of $\rho_{\iota}$ (i.e., $\rho_{-k}, \ldots, \rho_{-2}, \rho_{-1}$ ) is obtained via the pairwise product of all pre-intervention period dummies with the main treatment indicator. The lower limit $k$ varies depending on the intervention phase under evaluation. The interval is reflective of the $k$ periods approaching treatment in a single program year, with $\rho_{0}$ serving as the baseline estimand. ${ }^{25}$ The model excludes distant pre-event data that are more that $k$ periods before the intervention. ${ }^{26}$ Estimates of $\rho_{\iota}$ should be jointly indistinguishable from zero. Relative estimates close to the initial treatment may be plausibly bounded away from zero, in theory, and suggests possible anticipatory effects (Smith et al. 2002). However, in the absence of a theoretical framework for anticipation, any strong nonzero effects in the pre-treatment epoch would cast doubts on our assumption of trend equivalence and could be interpreted as selection bias (Lechner 2011).

Moreover, the natural logarithm of the residential precinct population size is incorporated into this specification as an offset rather than a covariate. The variable enters the model on the right-hand side but with its coefficient constrained to equal one. Algebraically maneuvering the exposure variable to the left-hand side and invoking the properties of logarithms results in an analysis of rates instead of counts. Though estimates are unlikely to vary drastically should the "absence" of shootings predominate across precincts and months,

\footnotetext{
${ }^{25}$ The calendar month immediately prior to program implementation in both years serves as the reference period. Excluded periods include June in 2014 and May in 2015.

${ }^{26}$ We do not model months earlier than January in both years.
} 
standardizing by "population-at-risk" nonetheless acknowledges the greater precision of rates in the face of larger population sizes (Osgood 2000).

Next, we follow with a separate fixed effects Poisson specification pooling all available years together. The 5-year panel results in over 60 'month-year' observations. Again, we explored the effects of all iterations of the SAO initiative on open-air shootings. Our timevarying treatment structure is the same as before with one lead and two lags of the main policy variable. As a final measure, we explored the sensitivity of the shooting data to longstanding precinct-specific time trends. New York City precincts have largely experienced a shared, secular decline in gun violence over the last twenty years. Much of this reduction in firearmrelated violence predated the SAO initiative, affecting jurisdictions most beleaguered by gun violence. Acknowledging this slow-moving shooting trend, we fit Model 4 which takes the following form:

$$
\log \left(y_{p, t}\right)=\varphi_{0 p}+\varphi_{1 p} t+\varphi_{2 p} t^{2}+\omega_{t}+\sum_{j=-2}^{1} \delta_{j} S A O_{p, t+j}+\log \left[\frac{n}{10,000}\right]
$$

where, as before, $\varphi_{0 p}$ denotes fixed effects for precincts. Here, $\varphi_{1 p} t$ and $\varphi_{2 p} t^{2}$ denotes the interaction of each precinct-specific effect with a linear and quadratic time trend, respectively. Multiplying by these trends absorbs any differential pre-existing shooting trajectories between SAO and non-SAO jurisdictions. Note, each additional component of this Poisson equation exists as before, with the exception of the exposure variable. 


\section{Results}

\section{Crime Indices}

Table 1 reports estimates for 2014 and 2015, separately. Columns indicate outcomes for various composite and disaggregated crime indices. Model 1 only reports estimates of $\delta$, the coefficients on the interaction terms. Results suggest the 2014 SAO initiative did not appreciably influence street-level crime rates. Its first iteration was not associated with a reduction in the violent crime rate, or more specifically, rates of assault and robbery. The 2014 SAO initiative was associated with a significant reduction in per capita property crime, though this decrease was small-a net average decrease of three felonious property crimes per 100,000 residents. Estimates suggest heterogeneity of effects, though drug and weapon-related crimes are primarily arrest-generating offenses. In addition, some evidence suggests the reporting of misdemeanor and petty offenses increased during the evaluation period.

\section{[Table 1 about here]}

DiD estimates for the 2015 SAO initiative were similarly weak and statistically insignificant. Mirroring program effects in the previous year, null findings were observed across all violent and property crime indices. In sum, results from year-specific DiD models suggest the SAO initiative did not have an appreciable, isolating impact on violent street crime during the summer months in any particular year.

Model 2 was fit to the full 5-year panel which investigates the effect of both iterations of the SAO initiative on several crime outcomes. To avoid extraneous output, dummies for precincts and months were omitted from tabular results. With the exception of property crime, we do not find evidence of an immediate effect of the SAO initiative on precinct-level street 
crime. Leading effects for drug and weapon-related offenses were significant and positive, which is not entirely surprising given the seizure of contraband accompanies many arrests. We interpret this effect with caution, as other pre-intervention arrest-generating activity may be responsible for any increase in crime reporting. ${ }^{27}$ Violent crime, in particular, does not vary with program implementation. Disaggregated rates of robbery and assault are statistically indistinguishable from zero. We also did not find any evidence suggesting a lasting impact of the SAO initiative on violent street crime beyond program termination. Burglary offenses were the only crimes where we did not restrict attention to "street" incidents. ${ }^{28}$ Two-thirds of burglary reports for the period under study list "private house" or "apartment" (i.e., multiple-dwelling) as the premise type. Their associated location type is often listed as "inside of" or "rear of" these physical structures. High-visibility foot patrols should thwart, or arguably displace, the commission of particularly stealthy offense types such as

\footnotetext{
${ }^{27}$ Few open-air drug and weapon-related offenses occur across months. Non-ignorable differences in pretreatment reporting trends may be partially responsible for any observed anticipatory effects. Drug and/or weapon-related crime reporting is typically fueled by geographically-focused arrest-generating activities. For example, the staffing of specialized units dedicated exclusively to narcotics enforcement has dwindled heavily in recent years, and as a result, their intensity has been concentrated in more drug-prone regions of the city. Anecdotal evidence suggests narcotics-related activity intensified in the pre-intervention period, as heightened SAO guardianship would typically disrupt the execution of "plainclothes" operations. Further, narcotics-related arrests, in general, have been declining over time. Most of the observed drug and/or weapon-related offenses in our sample involve crimes of simple possession. In particular, most reports involving drug possession are consistent with personal use-not distribution. Similarly, most weapon-related offense reports are consistent with non-firearm-related possession (e.g., knives and other blunt instruments). The SAO model of crime prevention was not designed to be an arrest-generating intervention strategy. Rather, most officers were encouraged to prevent crime by exercising their visible presence on street segments. We argue that any increase in drug and weaponrelated reporting are unlikely to be the result of intensifying visible foot patrols.

${ }^{28}$ Restricting burglary complaints to a subset of street offenses is limiting. Too few burglaries occur in public domains. To illustrate, larcenies from vehicles used by persons for commercial or business purposes would be classified as a burglary according to the New York State Penal Law (see, e.g., § 140.00 definition of "building"). Offenses of this type typically occur on visible street segments when the vehicle is unattended, and would be classified as a "street" burglary for crime reporting purposes. Less than five percent of burglaries for the years under study were listed as street offenses. Log-linear least-squares estimates would be affected by small per capita rates and low cardinality over time.
} 
burglary and motor vehicle theft. ${ }^{29}$ In all models, results suggest the widespread distribution of uniformed officers on foot within precinct jurisdictions does not influence general rates of burglary offenses or street thefts of motor vehicles.

\section{Shooting Incidents}

Table 2 reports results from Model 3 only, which explored the effects of the SAO initiative on open-air shootings in each year, separately. The estimate reported in Column 2 shows the 2014 SAO initiative produced a significant treatment effect. Exponentiation of our 2014 estimate for $\delta$ implies the 2014 initiative was associated with a 37\% reduction in the expected rate of total reported shootings (i.e., $e^{-0.46}=.63$ ). The 2015 coefficient also suggests negative program effects in its subsequent iteration, thought the effect in this year is substantially weaker and less precisely estimated. However, adjusting for calendar effects in the periods before SAO adoption dampens any observed effects (see Column 3). The 2014 coefficient in Column 3 is less precisely estimated once we explicitly model the periods approaching program exposure. Similarly, the 2015 estimate in Column 3 is also less precise and substantially smaller in magnitude. Results from Model 3 suggest that SAO adoption was, to a certain degree, partially determined by gun violence in the months prior to its implementation. ${ }^{30}$ Once we flexibly adjusted for shocks in the calendar months predating the

\footnotetext{
${ }^{29}$ Assessing crime displacement to nearby street segments is a complicated endeavor due to large units of analysis. Absent the precise deployment of foot patrols to micro-locations within precinct jurisdictions, we cannot directly quantify how the widespread surge in police presence affected adjacent beats or sectors.

${ }^{30}$ The coefficients in the pre-period were positive and relatively large in magnitude. The "absorbing" influence of pre-period dummies (i.e., 'lead' indicators) has been observed in other place-based evaluation strategies, particularly those where self-selection of jurisdictions into treatment was suggested. In their analysis of Operation Impact in New York City, MacDonald and colleagues (2016) observed that effects were weaker once they modeled the two periods before program exposure.
} 
foot patrol surge, the effect of the SAO initiative on shootings was indistinguishable from zero.

Column 3 also reports individual post-exposure period effects beneath the main interaction.

We explore the dynamics of SAO exposure in greater detail in the next section.

[Table 2 about here]

Note, year-specific equations focus on the subset of months immediately before and after the onset of SAO guardianship. Table 3 reports results from Model 4 which assesses the effect of the intermittent implementation of all SAO initiatives on open-air shootings over the 60-month observation period. Poisson estimates were smaller in magnitude once we allow for the estimation of fixed effects for precincts and months. Under this specification, we did not find evidence of an immediate effect of the SAO initiative on shootings. Further, we did not find evidence of gun violence abating in anticipation of police officials' promulgation of the SAO initiative's effective dates, nor did we find evidence suggesting a residual impact of treatment in months beyond program termination.

We also explicitly modeled cross-group diffusion via dummies for bordering jurisdictions never subjected to the SAO initiative. A positive coefficient suggests a spatial displacement of gun violence into neighboring jurisdictions. A negative coefficient suggests a diffusion of deterrence which carried over into non-SAO precincts. Lagging the variable by one period investigates any potential delayed effects in contiguous jurisdictions. Neither the neighbor dummy nor its lag produced a treatment effect. Effects were also small in magnitude.

Observed null effects for shooting incidents were robust to the inclusion of precinctspecific linear and quadratic time trends. Though computationally demanding as a modeling strategy, it buttresses claims of trend equivalence in years pre-dating the SAO initiative. 
Negligible differences in our point estimates demonstrates the insensitivity of results to alternative specifications.

\section{[Table 3 about here]}

\section{Robustness Tests}

Is the effect of foot patrols on crime constant or dynamic?

The difference-in-differences (DiD) estimators used thus far mostly assume constant treatment effects during the intervention phase. Our policy variables might obscure important intertemporal effects in the periods before and after SAO adoption. While each intervention is transient (i.e., 90 days), our goal in this section is to assess transitory trends in the immediate months surrounding the surge in street-level guardianship. Prior research indicates treatment effects exhibit volatility in the early stages of an intervention, with effects decaying over time (Sherman 1990; see also Sorg et al. 2013).

Figures 3 and 4 report dynamic coefficients for all crime outcomes. Each coefficient is the interaction of a treatment indicator with individual month dummies specific to SAO and non-SAO jurisdictions. We plot coefficients associated with the two periods before and the four periods after SAO adoption. Reported coefficients represent our dynamic effect window. Vertical bands bounding each monthly estimate represent $95 \%$ confidence intervals. Unless otherwise noted, our standard errors were clustered at the precinct-level to address observational dependence within precincts.

[Figure 3 and Figure 4 about here]

Our strongest observed effects were for property offenses, which concentrated during the intervention phase. Though effects change over time, they do not persist-and most quickly 
rebound to the baseline average once the initiative ends. Though not shown graphically, we also extended this dynamic framework to assess a third leading treatment effect. We did not find evidence of emerging group trends in the periods before baseline that would explain any observed effects post-program exposure.

To summarize, we assessed the effect of the SAO initiative across 9 crime indices. Two iterations of the SAO initiative were instituted within our 5-year sampling window. Dynamic effects were assessed separately, by year. Months 1 , 2, and 3 (i.e., $t_{-1}-t_{-3}$ ) overlap with the 90-day exposure, while period 4 onward indexes all months beyond program termination. Of the 36 post-period effects in the 2014 iteration (three during the exposure phase and one after for each of the nine crime outcomes), only three coefficients were negatively bounded away from zero, all of which were specific to property offenses. Of the 36 post-period effects in the 2015 iteration, only seven were bounded away from zero. Six of our confidence bands were negatively bounded away from zero, most of which were for non-violent offenses, and one was positive. Evidence suggests reported street robberies increased in the final month of the 2015 iteration, though the effect was transient and did not persist.

We also find little evidence of anticipatory effects. Of the 18 coefficient leads reported in each year, only two were bounded away from zero. The second lead for burglary in 2015 was strong and positive. However, this divergent differential trend in the pre-treatment epoch immediately stabilizes, and consequently does not persist into the post-period. ${ }^{31}$ Note, all

\footnotetext{
${ }^{31}$ Some reported crime metrics were more infrequent than others across time. Coefficients associated with several non-composite crime metrics (e.g., drug/weapon offenses), have small offense counts at the street level, and thus their rates will typically have high variance. On the other hand, the NYPD's composite crime indices (e.g., index crime) is more precisely estimated, as indicated by their tighter confidence bands.
} 
violent crime leads were relatively stable before the onset of the intervention. The SAO initiative, while directed within areas with disproportionately high violent crime rates, had largely ignored other citywide jurisdictions with similarly urgent crime concerns. As an additional robustness check, we assessed violent crime leads going back five months before each intervention. All coefficients were bounded around zero.

What is the counterfactual world of open-air gun violence?

Police departments typically prioritize their resources in problem areas where the concerns voiced by community residents are often crime-specific. Firearm-related violence, in particular, is geographically clustered, exhibiting greater concentration within specific regions of the city. While each community will be subjected to varying levels of personal and property crime within a given month, not all will experience a gun discharge as a consequence of those incidents.

To test the robustness of our shooting analyses, we reran the basic two-way fixed effects Poisson specification (i.e., Model 4) using only the SAO policy dummy. ${ }^{32}$ We then compared estimates from the base specification with independent estimates of the main policy dummy using three alternative control groups: (1) all precincts from within the same patrol borough $^{33},(2)$ all adjacent neighbors, and (3) SAO-adopters only. The pairing of the treated with

\footnotetext{
32 Over the 60-month observation period, the SAO policy dummy intermittently indexes a subset of precinct jurisdictions during two discrete but qualitatively similar iterations (i.e., $S A O_{p t}^{14}$ and $S A O_{p t}^{15}$ ). Again, the variable $S A O_{p t}$ is a dummy equal to unity if a precinct participated in the SAO initiative at any time and it was in the postexposure epoch (i.e., the 90 -day intervention phase). We dub $S A O_{p t}$ a static effect because it is a simple dummy intervention. Our goal is to assess the effects of the SAO initiative on open-air gun violence absent any timevarying treatment structure.

${ }^{33}$ The NYPD has eight patrol boroughs. The boroughs of Brooklyn, Queens, and Manhattan are split into a northern patrol borough and a southern patrol borough. Each has clearly demarcated borders and is headed by a separate
} 
the untreated within geographically proximate settings has been used in applied work, albeit using smaller observational units (Branas et al. 2011; MacDonald et al. 2016). Others have also leveraged the adjacency of untreated jurisdictions as a nonequivalent but useful counterfactual, suggesting that bordering units serve as suitable proxies for "almost-treated" units (Cavalcanti et al. 2019). Moreover, restricting samples to "adopter-only" jurisdictions has also been used in applied settings, more so to limit model identification to variation in treatment timing (see Wolfers 2006). In our evaluation, treatment exposure is intermittent, with some jurisdictions moving into and out of a treated status across time. Only future or previous receivers of the initiative serve as controls. Table 4 reports estimate of the main policy dummy under each alternative. All substitutes failed to yield any immediate effects of the SAO initiative on open-air gun violence, suggesting our null findings are robust to alternative control groups.

\section{[Table 4 about here]}

We also investigated the possibility of treatment effect heterogeneity by geography. This is analogous to a methodological approach employed by Branas and colleagues (2011), which assessed the effects of vacant lot greening in Philadelphia. Treated lots were randomly matched to a nearby control lot within the same region, and the effects of the greening project on crime and health outcomes were explored by city section. Despite our attempts to isolate experimental settings, we did not find any region-specific effects associated with program implementation.

\footnotetext{
borough commander in charge of patrol operations. This is a qualitatively different hierarchical position in the NYPD rank structure. A precinct commander is in charge of patrol operations within the confines of his or her assigned precinct. The borough commander will oversee all precinct commanders within the same patrol borough. Matching SAO jurisdictions with their patrol borough counterparts overlooks city sections where shootings do not cluster. Many of the future and previous receivers of the SAO initiative were sampled by NYPD executives from within the same patrol borough, offering a more homogenous counterfactual grouping.
} 
We also explored heterogeneous treatment effects by exploiting the timing of deployments (Green et al. 2014; Larsen et al. 2015). Not only was the SAO initiative a uniformed saturation of public space, but it also exhibited a temporal concentration on weekends and evenings. SAO officers were assigned steady patrol duty schedules; all 'days off' were concentrated midweek (i.e., Monday - Thursday). Thus, SAO jurisdictions received a consistent saturation of foot patrols on weekends throughout the 90-day intervention phase. Our 5-year sampling window shows nearly half of all open-air shootings occurred on weekends. Moreover, deployment times were not concentrated during typical business hours. In fact, SAO guardianship was most pronounced between 4:00 pm and 4:00 am. Over the 5-year panel, nearly three-quarters of all open-air shootings occurred during non-business (i.e., evening) hours. Table 5 reports separate estimates of the SAO policy dummy under alternative temporal limits. Neither the daily nor the hourly restrictions resulted in significant program effects.

\section{[Table 5 about here]}

We also assessed the dynamics of open-air gun violence separately from the NYPD's standard crime metrics. A year-specific treatment indicator was interacted with month dummies specific to SAO and non-SAO jurisdictions. Month dummies were included for periods 1 and 2 before SAO exposure in each year and months 1, 2, and 3 after. This is our "effect window" (see Schmidheiny \& Siegloch 2019). The baseline period (i.e., $t_{0}$ ) is the month before SAO adoption and is omitted as our reference period. Note, the months were binned beyond these time points. Month 3 before baseline is a dummy equal to unity in pre-treatment period 3 backward; likewise, month 4 after baseline is a dummy equal to unity in post-treatment period 
4 forward. ${ }^{34}$ Effects were assumed to be dynamic in between the endpoints, but constant beyond. Table 6 reports effects in the pre- and post-treatment epochs, separately, for each adoption year.

\section{[Table 6 about here]}

Pre-period coefficients do not suggest anticipatory effects, though we acknowledge the period before baseline in 2015 is strong, and positive..$^{35}$ Negative effects emerge in the initial months after SAO adoption, though they do not persist. We do, however, observe a strong, lasting negative effect carrying over into the months beyond the 2014 iteration, but this effect vanishes once we allow for precinct-specific time trends. ${ }^{36}$ Coefficients in Columns (1) through (3) in both years display a relatively consistent pattern.

Column (4) estimates dynamic treatment effects by comparing SAO precincts with all jurisdictions citywide-absent those precincts with a tangible border. The perception of offending risk in non-SAO jurisdictions sharing a territorial border poses a threat to our identification strategy. In other words, our "treatment" should not "spillover" into untreated jurisdictions (Duflo et al. 2007; Ryan et al. 2015). Estimates may be biased towards the null hypothesis should tightly bordered counterfactual jurisdictions become indirectly treated. ${ }^{37}$ To

\footnotetext{
${ }^{34}$ Autor (2003) displays event study estimates and "bins" the final post-treatment period; effects were assumed to be constant beyond this period. In most studies, researchers rarely report how they treat the periods beyond either side of the dynamic effect window (Schmidheiny \& Siegloch 2019).

${ }^{35}$ Shooting lead coefficients close to the SAO effective dates were mostly positive in both years, and a bit more precisely estimated in 2015. Though anticipatory effects were of substantive interest in this evaluation, we were also concerned with selection of SAO jurisdictions into treatment on the basis of past outcomes. The latter concern is entirely plausible, and is one of the reasons we modeled the shooting data more rigorously than the NYPD's standard crime metrics.

${ }^{36}$ Any precinct-specific linear or higher order polynomial trend fully absorbs the persistent effect observed in 2014.

${ }^{37}$ Augmenting visible guardianship on street segments might affect the perception of offending risk in non-SAO jurisdictions if foot patrols concentrated near the periphery of SAO precinct borders - or beyond. Discarding all neighbors thus compares SAO precincts with those jurisdictions that are more geospatially remote. We have no evidence that a nonadjacent counterfactual would be influenced by the widespread surge in foot patrols within
} 
account for this, our final model isolates experimental settings by excluding from our sample any counterfactual jurisdiction sharing at least one traversable border with a treated precinct. Coefficients increase in size but were imprecisely estimated using smaller subsamples. In general, null effects hold even after removing jurisdictions with a porous territorial border.

\section{Does deterrence stop at precinct borders?}

In the previous section, we discussed the possibly of a diffusion of deterrence beyond the periphery of treated jurisdictions. We argue that if shooting events did transcend precinct borders, then the shift, whether transitory or persistent, is likely local. To account this, we implemented a placebo treatment whereby SAO neighbors (those most likely to be affected by spillovers) are defined as the treated units. We then used all other citywide jurisdictionsexcluding those originally selected to receive foot patrols-as the control group. The lead-lag structure was maintained. Coefficients associated with the placebo policy were negative, though indistinguishable from zero. We find no detectable impact on criminal offending or firearm-related violence among SAO neighbors. This refutes any suggestion that a diffusion of deterrence beyond the periphery of SAO jurisdictions biased our results towards zero. Tabular results associated with our placebo treatment procedure are available upon request.

As a final note, observed effects for shootings showed more volatility in the pretreatment epoch and considerably more variation in specific regions (i.e., boroughs) of New

SAO precincts. As well, if SAO officers were deployed on foot directly from their assigned SAO precincts - and not from their previous administrative facilities - then marked vehicular travel to and from SAO precincts would not inadvertently create the impression of more police presence within non-SAO precincts. The perception of police intensity in comparison areas is a noteworthy critique in experimental studies and biases results towards zero (see Larson 1975). Our understanding of the intervention suggests SAO exposure was limited to within precinct borders, though we cannot completely rule out treatment spillover. 
York City. As such, we modeled the NYPD shooting data more rigorously than the crime metrics. Null findings observed for open-air gun violence survive an exhaustive set of alternative specifications and multiple qualitatively disparate counterfactual groupings.

\section{Limitations}

Our study is not without limitations. First, using reported crimes as a main outcome of interest may be problematic. On the one hand, a heightened foot patrol presence may cause residents to become resentful, and thus unwillingly to share information with the police or even report victimization (see Kochel 2011; Rosenbaum 2006; but, cf., Weisburd et al. 2011). On the other hand, this formal presence increases the frequency of contact between citizens and officers, perhaps resulting in a net increase in crimes reported to the police. The latter consequence may actually encourage residents to report victimization. While this may, paradoxically, improve the accuracy of crime reporting, it potentially dilutes the preventive effects of expanding the spatial reach of formal guardianship within communities.

Second, we are unable to control for other situational crime prevention strategies occurring contemporaneously with the "Summer All Out" (SAO) initiative, such as Operation Impact ${ }^{38}$, the Neighborhood Coordination Officer (NCO) program, and the piloting of Operation Ceasefire in Brooklyn towards the end of 2014. Any suppression of violence associated with these programs potentially confounds the effects of the SAO initiative.

Third, we only model treatment dichotomously. A more sophisticated evaluation approach would be to model treatment in dosages. Acquiring a continuous measure of precinct

\footnotetext{
${ }^{38}$ Operation Impact was in effect from January 2003 to mid-July 2014.
} 
staffing would allow us to explicitly model a dose treatment, and identify how crime fluctuates at different staffing dosages (Mazeika 2014). Empirically modeling treatment in dosages has surfaced in applied work, and DiD methods are conducive to such measures (Abadie \& Dermisi 2008; Acemoglu et al. 2004; Pedraja-Chaparro et al. 2016). Presently, it is unclear how fruitful of an endeavor it might be to address the nonuniform allocation of SAO officers. Most jurisdictions received a large baseline contingent of personnel, with only a few participating precincts receiving more than the average allotment. Moreover, proprietary concerns voiced by the NYPD rendered most staffing and personnel records unavailable for public consumption.

It is also worth noting that precinct geography complicates empirical assessments of dose effects in two seemingly interrelated ways. We cannot disentangle dosages of sentinelbased foot patrols from other concurrent resource deployments (e.g., motorized patrol response) within precinct jurisdictions. As well, large units of analysis obfuscate inferences drawn from the explicit modeling of law enforcement intensity, or lack thereof. Disaggregating our unit of analysis to smaller geographic locales (e.g., block-group level) would allow us to isolate smaller experimental segments within precincts to serve as viable control areas. We could not delineate the spatial reach of SAO foot patrols within precinct borders. Prior research suggests experimental evaluations of place-based enforcement strategies are often complicated by the units of analysis (Weisburd et al. 2008). Thus, the designation of large geographic regions as units of analysis (i.e., precincts) could potentially bias estimates of a program effect, with negative effects indicative of the collective law enforcement strategies aimed at reducing crime and disorder (Piza \& O’Hara 2014). 


\section{Discussion}

Traditionally, American policing has been characterized by an emphasis on randomized patrolling, rapid response to calls, and reactive investigations of criminal incidents (Sherman 2013). Yet since the 1980 s, the focus of managing police resources has shifted to "targeting, testing, and tracking" (Nagin et al. 2015: 77). Nevertheless, there is still substantial discussion of what impact the police can (Cullen \& Pratt 2016) and should (Sweeten 2016) have on aggregate crime levels, and which strategies work best to achieve those impacts (Braga et al. 2014; Braga \& Weisburd 2012).

The present study suggests a weak, negligible influence of high-visibility, saturation foot patrols on aggregate rates of criminal offending. Using a nonequivalent control group and a difference-in-differences (DiD) experimental design, we tested the effect of the "Summer All Out" (SAO) initiative on reported crimes and shootings. Our results indicate aggregate rates of street crime do not vary with the deployment, or withdrawal, of SAO foot patrols. The 2014 SAO initiative was not associated with significant reductions in reported index crime or disaggregated rates of robbery and assault. Null effects were also observed in its subsequent iteration; all major crime indices in 2015 were similarly bounded around zero. The present evaluation also suggests foot patrol deployments did not appreciably reduce shootings at the street level. Overall, the sharp dispersal of SAO officers within precinct jurisdictions appears to be ineffective at reducing violent street crime or open-air gun violence.

Due to the NYPD's multifaceted support network, police executives have the ability to mobilize large numbers of surplus personnel to participate in parades, large-scale demonstrations, and other unplanned events. These mobilizations are typically brief, lasting 
only a few hours or several days. But the SAO initiative was different. The sharp dispersal of uniformed officers lasted for 90 days, and was one of the largest and longest mobilizations to augment patrol operations in the NYPD's history. Each SAO mobilization was large in absolute terms, both in personnel and geographic distribution. The diffuse dispersal of visible guardianship on foot across precinct jurisdictions may have diluted any potential crime suppression benefits. Nevertheless, there is no indication that the NYPD is planning to cease SAO deployments in the future.

The present study may offer guidance for future research and policymaking. First, the NYPD should subject well-advertised, department-sponsored initiatives to empirical evaluation. Such evaluation is necessary to establish a program's effectiveness. Internal evaluations of place-based enforcement strategies designed to suppress crime and disorder should be coproduced with local research institutions, allowing for the scientific advancement-and accumulation - of a growing body of evidence-based enforcement strategies. Reproducible results should then guide future policy and agency directives (see Risman 1980). We are not aware of any internal NYPD sanctioned research group that is proactively publishing peerreviewed impact evaluations of department-sponsored crime initiatives.

Law enforcement agencies, in general, should have a vested interest in the systematic evaluation of their own self-initiated crime prevention efforts to reduce violence. We showed earlier that repeated experimentation of the SAO initiative in communities across the city is costly. Weighing the financial strain of continued experimentation against other community policing efforts is critical moving forward, as budgetary coffers only swell to ensure the continued expansion of high-visibility policing. 
Second, while visible policing itself should deter criminal behavior (Nagin et al. 2015), the content of officer behavior in specific places does matter (Cullen \& Pratt 2016). Unfortunately, resource allocation strategies supporting the SAO initiative were opaque. If the SAO initiative continues, efforts should focus on process evaluation during the intervention period in order to get inside the "black box" of how these officers are allocated (Haberman \& Stiver 2018; Wood et al. 2014). Department executives should make concerted efforts to adjust the content of officer behavior throughout the intervention phase. Moreover, strategic planners should employ entirely different situational crime prevention strategies (e.g., problem-oriented policing) if a similar intervention is to be implemented in successive years. The 2014 and 2015 initiatives were designed with a similar blueprint. SAO officers served a basic sentinel function for an approximate three-month intervention period. We recommend police departments instead experiment with a diverse range of community and intelligence-led policing initiatives.

Third, the widespread distribution of officers on foot across expansive geographies may have been too diffuse too affect offenders' perception of offending risk (see Sorg et al. 2017). The SAO initiative was not a concentrated exposure of visible guardianship. Macro-dispersal of uniformed officers across densely populated regions may dilute the salience of the initiative. This would be consistent with the broader literature on community crime prevention, which is generally mixed, but with stronger evidence for interventions aimed at crime hot spots (Braga et al. 2014; Lum et al. 2011; Telep \& Hibdon 2018). Hot spot size varies across studies (Sherman et al. 1989; Sherman \& Weisburd 1995), but they are typically far smaller than the precinct jurisdictions chosen to participate in the SAO initiative (Weisburd 2015). The SAO initiative, and 
others like it, should consider interventions at smaller units of geography, both to allow for clearer assessments of their effectiveness and to allow for more efficient use of departmental resources (Telep \& Hibdon 2018; see also Eck 2015; Kennedy 2016; Weisburd et al. 2014).

Fourth, the intensity or frequency by which SAO officers police their beats is potentially a function of their familiarity with their assigned jurisdictions. SAO officers were deployed on foot in relative isolation and with little knowledge of local crime conditions and the offending population. In addition, anecdotal evidence suggests SAO officers received insufficient time to adjust to their new environments and odd patrol duty schedules. ${ }^{39}$ Some evidence even suggests SAO officers received minimal supervisory oversight. ${ }^{40}$ Arguably, the selection of officers with less community awareness might offset any potential crime control gains. Lastly, while randomized controlled trials (RCTs) have unparalleled power to establish causality, they may not always provide robust accounts of the sort of "counterfactual worlds" that practitioners and policymakers desire (see Nagin \& Sampson 2019; Sampson 2010). Quasiexperimental studies, in particular the varied DiD approaches employed here, provides a useful addition to RCTs, as well as other post-hoc matching estimators used to identify treatment

\footnotetext{
39 The NYPD mandated that all SAO officers receive, in aggregate, a one-day refresher course to reacclimate members to street-level patrol work. We have no evidence that attendees received detailed instruction regarding any community-derived intelligence specific of their individually assigned jurisdictions

${ }^{40}$ Maintaining the perception of increased guardianship over time is not easy. The NYPD did not sanction any governing body to ensure the visibility of SAO officers during the intervention phase. Supervision of SAO personnel was relegated to the supervisory staff permanently assigned to participating SAO jurisdictions. Thus, as the rankand-file staff increased due to the influx of SAO personnel, the supervisory component did not. Throughout the initiative, patrol supervisors were thus in charge of supervising regular patrol duty operations and ensuring the continued visibility of the SAO contingent on foot. This greatly increases the 'span of control' of supervisory members at the local level. Effects might thus be severely understated if precinct-level management could not maintain the visibility of SAO officers during peak crime hours. We have no evidence that precinct-level supervisors were making frequent or varied visits to SAO officers on foot. In sum, if foot deployments were too sparse and sufficiently interrupted by officer absence from their assigned posts, then the perception of "more presence" is even more diluted.
} 
effects. Police officials benefit greatly from evidence about the causal nature of populationlevel interventions in policing, even when those exposures are confounded by design. As resource limitations direct law enforcement efforts to some jurisdictions and not others, DiD estimation strategies present crucial opportunities to evaluate the causal impact of those interventions. 


\section{REFERENCES}

Abadie, A., \& Dermisi, S. (2008). Is terrorism eroding agglomeration economies in Central Business Districts? Lessons from the office real estate market in downtown Chicago. Journal of Urban Economics, 64(2), 451-463. doi:10.1016/j.jue.2008.04.002

Acemoglu, D., Autor, David H., \& Lyle, D. (2004). Women, War, and Wages: The Effect of Female Labor Supply on the Wage Structure at Midcentury. Journal of Political Economy, 112(3), 497-551. doi:10.1086/383100

Angrist, J. D., \& Pischke, J.-S. (2009). Mostly Harmless Econometrics: An Empiricist's Companion. Princeton, NJ: Princeton University Press.

Apel, R. (2013). Sanctions, Perceptions, and Crime: Implications for Criminal Deterrence. Journal of Quantitative Criminology, 29(1), 67-101. doi:10.1007/s10940-012-9170-1

Autor, David H. (2003). Outsourcing at Will: The Contribution of Unjust Dismissal Doctrine to the Growth of Employment Outsourcing. Journal of Labor Economics, 21(1), 1-42. doi:10.1086/344122

Azoulay, P., Fons-Rosen, C., \& Graff Zivin, J. S. (2019). Does Science Advance One Funeral at a Time? American Economic Review, 109(8), 2889-2920. doi:10.1257/aer.20161574

Baumer, E. P., \& Wolff, K. T. (2014). Evaluating Contemporary Crime Drop(s) in America, New York City, and Many Other Places. Justice Quarterly, 31(1), 5-38. doi:10.1080/07418825.2012.742127

Beccaria, C. (1963). On Crimes and Punishments. Indianapolis, IN: Bobbs-Merrill.

Becker, G. S. (1968). Crime and Punishment: An Economic Approach. Journal of Political Economy, 76(2), 169-217.

Bertrand, M., Duflo, E., \& Mullainathan, S. (2004). How Much Should We Trust Differences-InDifferences Estimates? The Quarterly Journal of Economics, 119(1), 249-275. doi:10.1162/003355304772839588

Blundell, R., \& MaCurdy, T. (1999). Labor Supply: A Review of Alternative Approaches. In O. C. Ashenfelter \& D. Card (Eds.), Handbook of Labor Economics (Vol. 3A, pp. 1559-1695). Amsterdam: Elsevier.

Bowers, W. J., \& Hirsch, J. H. (1987). The impact of foot patrol staffing on crime and disorder in Boston: An unmet promise. American Journal of Policing, 6, 17-44.

Braga, A. A., \& Bond, B. J. (2008). Policing crime and disorder hot spots: A randomized control trial. Criminology, 46(3), 577-607. doi:10.1111/j.1745-9125.2008.00124.x 
Braga, A. A., Papachristos, A. V., \& Hureau, D. M. (2012). Hot spots policing effects on crime. Campbell Systematic Reviews, 8. doi:10.4073/csr.2012.8

Braga, A. A., Papachristos, A. V., \& Hureau, D. M. (2014). The Effects of Hot Spots Policing on Crime: An Updated Systematic Review and Meta-Analysis. Justice Quarterly, 31(4), 633663. doi:10.1080/07418825.2012.673632

Braga, A. A., Weisburd, D., \& Turchan, B. (2018). Focused Deterrence Strategies and Crime Control. Criminology \& Public Policy, 17(1), 205-250. doi:10.1111/1745-9133.12353

Braga, A. A., \& Weisburd, D. L. (2012). The Effects of Focused Deterrence Strategies on Crime:A Systematic Review and Meta-Analysis of the Empirical Evidence. Journal of Research in Crime and Delinquency, 49(3), 323-358. doi:10.1177/0022427811419368

Braga, A. A., Zimmerman, G., Barao, L., Farrell, C., Brunson, R. K., \& Papachristos, A. V. (2019). Street Gangs, Gun Violence, and Focused Deterrence: Comparing Place-based and Group-based Evaluation Methods to Estimate Direct and Spillover Deterrent Effects. Journal of Research in Crime and Delinquency. doi:10.1177/0022427818821716

Branas, C. C., Cheney, R. A., MacDonald, J. M., Tam, V. W., Jackson, T. D., \& Ten Have, T. R. (2011). A Difference-in-Differences Analysis of Health, Safety, and Greening Vacant Urban Space. American Journal of Epidemiology, 174(11), 1296-1306. doi:10.1093/aje/kwr273

Brown, M. K. (1988). Working the Street: Police Discretion and the Dilemmas of Reform. New York: Russell Sage Foundation.

Cameron, A. C., Gelbach, J. B., \& Miller, D. L. (2011). Robust Inference With Multiway Clustering. Journal of Business \& Economic Statistics, 29(2), 238-249. doi:10.1198/jbes.2010.07136

Cavalcanti, T., Da Mata, D., \& Toscani, F. (2019). Winning the oil lottery: the impact of natural resource extraction on growth. Journal of Economic Growth, 24(1), 79-115. doi:10.1007/s10887-018-09161-z

Chainey, S., \& Ratcliffe, J. H. (2005). GIS and Crime Mapping. New York: Wiley.

Cohen, L. E., \& Felson, M. (1979). Social Change and Crime Rate Trends: A Routine Activity Approach. American Sociological Review, 44(4), 588-608. doi:10.2307/2094589

Cook, P. J. (1980). Research in Criminal Deterrence: Laying the Groundwork for the Second Decade. Crime and Justice, 2, 211-268. doi:10.1086/449070

Corsaro, N., \& Engel, R. S. (2015). Most Challenging of Contexts: Assessing the Impact of Focused Deterrence on Serious Violence in New Orleans. Criminology \& Public Policy, 14(3), 471-505. doi:10.1111/1745-9133.12142 
Cowell, B. M., \& Kringen, A. L. (2016). Engaging communities one step at a time: Policing's tradition of foot patrol as an innovative community engagement strategy. Washington, DC: Police Foundation.

Cullen, F. T., \& Pratt, T. C. (2016). Toward a Theory of Police Effects. Criminology \& Public Policy, 15(3), 799-811. doi:10.1111/1745-9133.12231

Driscoll, J. C., \& Kraay, A. C. (1998). Consistent Covariance Matrix Estimation with Spatially Dependent Panel Data. The Review of Economics and Statistics, 80(4), 549-560. doi:10.1162/003465398557825

Duflo, E., Glennerster, R., \& Kremer, M. (2007). Using Randomization in Development Economics Research: A Toolkit. In T. P. Schultz \& J. A. Strauss (Eds.), Handbook of Development Economics (Vol. 4, pp. 3895-3962): Elsevier.

Eck, J. E. (2015). Who Should Prevent Crime at Places? The Advantages of Regulating Place Managers and Challenges to Police Services. Policing: A Journal of Policy and Practice, 9(3), 223-233. doi:10.1093/police/pav020

Eck, J. E., \& Maguire, E. R. (2006). Have Changes in Policing Reduced Violent Crime? An Assessment of the Evidence. In A. Blumstein \& J. Wallman (Eds.), The Crime Drop in America. Cambridge, UK: Cambridge University Press.

Eck, J. E., \& Weisburd, D. L. (1995). Crime places in crime theory. In J. E. Eck \& D. L. Weisburd (Eds.), Crime and Place. Monsey, NY: Criminal Justice Press.

Eterno, J. A., \& Silverman, E. B. (2012). The Crime Numbers Game: Management by Manipulation. Boca Raton, FL: CRC Press.

Felson, M. (1994). Crime and Everyday Life: Insight and Implications for Society. Thousand Oaks, CA: Pine Forge Press.

Felson, M. (1995). Those who discourage crime. In J. E. Eck \& D. L. Weisburd (Eds.), Crime and Place. Monsey, NY: Criminal Justice Press.

Floyd, et al. v. City of New York, et al., 959 F. Supp. 2d 540 (2013).

Gertler, P. J., Martinez, S., Premand, P., Rawlings, L. B., \& Vermeersch, C. M. J. (2016). Impact Evaluation in Practice (2nd ed.). Washington, DC: The World Bank.

Granger, C. W. J. (1969). Investigating Causal Relations by Econometric Models and Crossspectral Methods. Econometrica, 37(3), 424-438. doi:10.2307/1912791

Green, C. P., Heywood, J. S., \& Navarro, M. (2014). Did liberalising bar hours decrease traffic accidents? Journal of Health Economics, 35, 189-198.

doi:10.1016/j.jhealeco.2014.03.007 
Grinols, E. L., \& Mustard, D. B. (2006). Casinos, Crime, and Community Costs. The Review of Economics and Statistics, 88(1), 28-45. doi:10.1162/rest.2006.88.1.28

Haberman, C. P., \& Stiver, W. H. (2018). The Dayton Foot Patrol Program: An Evaluation of Hot Spots Foot Patrols in a Central Business District. O(0), 1098611118813531. doi:10.1177/1098611118813531

Kelling, G. L., Pate, A., Dieckman, D., \& Brown, C. E. (1974). The Kansas City preventive patrol experiment. Washington, DC: Police Foundation.

Kelling, G. L., Pate, A., Ferrara, A., Utne, M., \& Brown, C. E. (1981). The Newark foot patrol experiment. Washington, DC: Police Foundation.

Kennedy, D. M. (2016). Community Crime Prevention. In T. G. Blomberg, J. M. Brancale, K. M. Beaver, \& W. D. Bales (Eds.), Advancing Criminology and Criminal Justice Policy (pp. 92103). New York: Routledge.

Kleck, G., \& Barnes, J. C. (2014). Do More Police Lead to More Crime Deterrence? Crime \& Delinquency, 60(5), 716-738. doi:10.1177/0011128710382263

Kochel, T. R. (2011). Constructing Hot Spots Policing: Unexamined Consequences for Disadvantaged Populations and for Police Legitimacy. Criminal Justice Policy Review, 22(3), 350-374. doi:10.1177/0887403410376233

Krivo, L. J. (2014). Placing the Crime Decline in Context: A Comment on Baumer and Wolff. Justice Quarterly, 31(1), 39-42. doi:10.1080/07418825.2012.742125

Kubrin, C. E., Messner, S. F., Deane, G., McGeever, K., \& Stucky, T. D. (2010). Proactive Policing and Robbery Rates Across U.S. Cities. Criminology, 48(1), 57-97. doi:10.1111/j.17459125.2010.00180.x

Larsen, B. Ø., Kleif, H. B., \& Kolodziejczyk, C. (2015). The volunteer programme 'Night Ravens': a difference-in-difference analysis of the effects on crime rates. Journal of Scandinavian Studies in Criminology and Crime Prevention, 16(1), 2-24. doi:10.1080/14043858.2015.1015810

Larson, R. C. (1975). What happened to patrol operations in Kansas city? A review of the Kansas city preventive patrol experiment. Journal of Criminal Justice, 3(4), 267-297. doi:10.1016/0047-2352(75)90034-3

Lechner, M. (2011). The Estimation of Causal Effects by Difference-in-Difference Methods. Foundations and Trends ${ }^{\circledR}$ in Econometrics, 4(3), 165-224. doi:10.1561/0800000014

Lum, C., Koper, C. S., \& Telep, C. W. (2011). The Evidence-Based Policing Matrix. Journal of Experimental Criminology, 7(1), 3-26. doi:10.1007/s11292-010-9108-2 
MacDonald, J., Fagan, J., \& Geller, A. (2016). The Effects of Local Police Surges on Crime and Arrests in New York City. PLOS One, 11(6), e0157223.

doi:10.1371/journal.pone.0157223

Macedo, D., Schuck, G., \& Kramer, M. (2015). NYPD Cops Flood High-Crime Areas In 'Summer All Out' Initiative. WLNY TV 10/55 - CBS New York.

Manning, P. K. (1977). Police Work: The Social Organization of Policing. Cambridge, MA: MIT Press.

Marvell, T. B., \& Moody, C. E. (1996). Specification problems, police levels, and crime rates. Criminology, 34(4), 609-646. doi:10.1111/j.1745-9125.1996.tb01221.x

Mazeika, D. M. (2014). General and Specific Displacement Effects of Police Crackdowns: Criminal Events and "Local" Criminals. (Ph.D. Dissertation), University of Maryland, College Park,

Meyer, B. D. (1995). Natural and Quasi-Experiments in Economics. Journal of Business \& Economic Statistics, 13(2), 151-161. doi:10.1080/07350015.1995.10524589

Nagin, D. S. (2013). Deterrence in the Twenty-First Century. Crime and Justice, 42(1), 199-263. doi:10.1086/670398

Nagin, D. S., \& Sampson, R. J. (2019). The Real Gold Standard: Measuring Counterfactual Worlds That Matter Most to Social Science and Policy. Annual Review of Criminology, 2(1), 123145. doi:10.1146/annurev-criminol-011518-024838

Nagin, D. S., Solow, R. M., \& Lum, C. (2015). Deterrence, Criminal Opportunities, and Police. Criminology, 53(1), 74-100. doi:10.1111/1745-9125.12057

National Research Council. (2004). Fairness and Effectiveness in Policing: The Evidence. Washington, DC: The National Academies Press.

Nixon, T. S., \& Barnes, J. C. (2018). Calibrating Student Perceptions of Punishment: A Specific Test of General Deterrence. American Journal of Criminal Justice . doi:10.1007/s12103018-9466-2

Novak, K. J., Fox, A. M., Carr, C. M., \& Spade, D. A. (2016). The efficacy of foot patrol in violent places. Journal of Experimental Criminology, 12(3), 465-475. doi:10.1007/s11292-0169271-1

Osgood, D. W. (2000). Poisson-Based Regression Analysis of Aggregate Crime Rates. Journal of Quantitative Criminology, 16(1), 21-43. doi:10.1023/a:1007521427059

Pate, A. M. (1986). Experimenting with foot patrol: The Newark experience. In D. P. Rosenbaum (Ed.), Community Crime Prevention: Does it Work? Newbury Park, CA: Sage. 
Pedraja-Chaparro, F., Santín, D., \& Simancas, R. (2016). The impact of immigrant concentration in schools on grade retention in Spain: A difference-in-differences approach. Applied Economics, 48(21), 1978-1990. doi:10.1080/00036846.2015.1111989

Petersen, M. A. (2008). Estimating Standard Errors in Finance Panel Data Sets: Comparing Approaches. The Review of Financial Studies, 22(1), 435-480. doi:10.1093/rfs/hhn053

Pickett, J. T., \& Roche, S. P. (2016). Arrested Development: Misguided Directions in Deterrence Theory and Policy. Criminology \& Public Policy, 15(3), 727-751. doi:10.1111/17459133.12217

Piza, E. L. (2018). The Effect of Various Police Enforcement Actions on Violent Crime: Evidence From a Saturation Foot-Patrol Intervention. Criminal Justice Policy Review, 29(6-7), 611629. doi:10.1177/0887403417725370

Piza, E. L., \& O’Hara, B. A. (2014). Saturation Foot-Patrol in a High-Violence Area: A QuasiExperimental Evaluation. Justice Quarterly, 31(4), 693-718. doi:10.1080/07418825.2012.668923

Pogarsky, G., \& Loughran, T. A. (2016). The Policy-to-Perceptions Link in Deterrence. Criminology \& Public Policy, 15(3), 777-790. doi:10.1111/1745-9133.12241

Pratt, T. C., Cullen, F. T., Blevins, K. R., Daigle, L. E., \& Madensen, T. D. (2006). The empirical status of deterrence theory: A meta-analysis. Taking stock: The status of criminological theory, 15, 367-396.

Press, S. J. (1971). Some Effects of an Increase in Police Manpower in the 20th Precinct of New York City. Santa Monica, CA: RAND Corporation.

Ratcliffe, J. H., Taniguchi, T., Groff, E. R., \& Wood, J. D. (2011). The Philadelphia Foot Patrol Experiment: A randomized controlled trial of police patrol effectiveness in violent crime hotspots. Criminology, 49(3), 795-831. doi:10.1111/j.1745-9125.2011.00240.x

Reaves, B. A. (2015). Local Police Departments, 2013: Personnel, Policies, and Practices. Washington, DC: U.S. Department of Justice, Bureau of Justice Statistics.

Risman, B. J. (1980). The Kansas City Preventive Patrol Experiment:A Continuing Debate. Evaluation Review, 4(6), 802-808. doi:10.1177/0193841x8000400605

Rosenbaum, D. P. (2006). The Limits of Hot Spots Policing. In D. Weisburd \& A. A. Braga (Eds.), Police Innovation: Contrasting Perspectives (pp. 245-263). New York: Cambridge University Press.

Rosenbaum, D. P., \& Lurigio, A. J. (1994). An Inside Look at Community Policing Reform: Definitions, Organizational Changes, and Evaluation Findings. Crime \& Delinquency, 40(3), 299-314. doi:10.1177/0011128794040003001 
Ryan, A. M. (2009). Effects of the Premier Hospital Quality Incentive Demonstration on Medicare Patient Mortality and Cost. Health Services Research, 44(3), 821-842. doi:10.1111/j.1475-6773.2009.00956.x

Ryan, A. M., Burgess, J. F., \& Dimick, J. B. (2015). Why We Should Not Be Indifferent to Specification Choices for Difference-in-Differences. Health Services Research, 50(4), 1211-1235. doi:10.1111/1475-6773.12270

Sampson, R. J. (2010). Gold Standard Myths: Observations on the Experimental Turn in Quantitative Criminology. Journal of Quantitative Criminology, 26(4), 489-500. doi:10.1007/s10940-010-9117-3

Sampson, R. J., \& Cohen, J. (1988). Deterrent Effects of the Police on Crime: A Replication and Theoretical Extension. Law \& Society Review, 22(1), 163-189. doi:10.2307/3053565

Schmidheiny, K., \& Siegloch, S. (2019). On Event Studies and Distributed-Lags in Two-Way Fixed Effects Models: Identification, Equivalence, and Generalization. CEPR Discussion Paper No. DP13477.

Sherman, L. W. (1990). Police Crackdowns: Initial and Residual Deterrence. Crime and Justice, 12, 1-48. doi:10.1086/449163

Sherman, L. W. (2013). The rise of evidence-based policing: Targeting, testing, and tracking. In M. Tonry (Ed.), Crime and Justice: A Review of Research (Vol. 42). Chicago, IL: University of Chicago Press.

Sherman, L. W., Gartin, P. R., \& Buerger, M. E. (1989). Hot Spots of Predatory Crime: Routine Activities and the Criminology of Place. Criminology, 27(1), 27-56. doi:10.1111/j.17459125.1989.tb00862.x

Sherman, L. W., \& Weisburd, D. (1995). General deterrent effects of police patrol in crime "hot spots": A randomized, controlled trial. Justice Quarterly, 12(4), 625-648. doi:10.1080/07418829500096221

Smith, M. J., Clarke, R. V., \& Pease, K. (2002). Anticipatory benefits in crime prevention. Crime Prevention Studies, 13, 71-88.

Sorg, E. T., Haberman, C. P., Ratcliffe, J. H., \& Groff, E. R. (2013). Foot Patrol in Violent Crime Hot Spots: The Longitudinal Impact of Deterrence and Posttreatment Effects of Displacement. Criminology, 51(1), 65-101. doi:10.1111/j.1745-9125.2012.00290.x

Sorg, E. T., Wood, J. D., Groff, E. R., \& Ratcliffe, J. H. (2017). Explaining Dosage Diffusion During Hot Spot Patrols: An Application of Optimal Foraging Theory to Police Officer Behavior. Justice Quarterly, 34(6), 1044-1068. doi:10.1080/07418825.2016.1244286 
St. Clair, T., \& Cook, T. D. (2015). Difference-in-Differences Methods in Public Finance. National Tax Journal, 68(2), 319-338. doi:10.17310/ntj.2015.2.04

Sweeten, G. (2016). What Works, What Doesn't, What's Constitutional? Criminology \& Public Policy, 15(1), 67-73. doi:10.1111/1745-9133.12176

Telep, C. W., \& Hibdon, J. (2018). Community Crime Prevention in High-Crime Areas: The Seattle Neighborhood Group Hot Spots Project. City \& Community. doi:10.1111/cico.12342

Telep, C. W., \& Weisburd, D. (2018). The Criminology of Places. In G. Bruinsma \& S. Johnson (Eds.), The Oxford Handbook of Environmental Criminology (pp. 583-603). New York: Oxford University Press.

Thompson, S. B. (2011). Simple formulas for standard errors that cluster by both firm and time. Journal of Financial Economics, 99(1), 1-10. doi:10.1016/j.jfineco.2010.08.016

Trojanowicz, R. C., \& Baldwin, R. (1982). An evaluation of the neighborhood foot patrol program in Flint, Michigan. East Lansing, MI: Michigan State University.

Venkataramani, A. S., Cook, E., O’Brien, R. L., Kawachi, I., Jena, A. B., \& Tsai, A. C. (2019). College affirmative action bans and smoking and alcohol use among underrepresented minority adolescents in the United States: A difference-in-differences study. PLOS Medicine, 16(6), e1002821. doi:10.1371/journal.pmed.1002821

Wakefield, A. (2007). Carry on Constable? Revaluing Foot Patrol. Policing: A Journal of Policy and Practice, 1(3), 342-355. doi:10.1093/police/pam038

Weisburd, D. (2015). The law of crime concentration and the criminology of place. Criminology, 53(2), 133-157. doi:10.1111/1745-9125.12070

Weisburd, D., Groff, E. R., \& Yang, S.-M. (2014). Understanding and Controlling Hot Spots of Crime: The Importance of Formal and Informal Social Controls. Prevention Science, 15(1), 31-43. doi:10.1007/s11121-012-0351-9

Weisburd, D., Hinkle, J. C., Famega, C., \& Ready, J. (2011). The possible "backfire" effects of hot spots policing: An experimental assessment of impacts on legitimacy, fear and collective efficacy. Journal of Experimental Criminology, 7(4), 297-320. doi:10.1007/s11292-0119130-z

Weisburd, D., Morris, N. A., \& Ready, J. (2008). Risk-Focused Policing at Places: An Experimental Evaluation. Justice Quarterly, 25(1), 163-200. doi:10.1080/07418820801954647

Weisburd, D., Wyckoff, L. A., Ready, J., Eck, J. E., Hinkle, J. C., \& Gajewski, F. (2006). Does crime just move around the corner? A controlled study of spatial displacement and diffusion of crime control benefits. Criminology, 44(3), 549-592. doi:10.1111/j.1745-

9125.2006.00057.x 
Wilson, J. Q. (1968). Varieties of Police Behavior: The Management of Law and Order in Eight Communities. Cambridge, MA: Harvard University Press.

Wilson, J. Q. (2013). Thinking About Crime: Basic Books.

Wilson, J. Q., \& Boland, B. (1978). The Effect of the Police on Crime. Law \& Society Review, 12(3), 367-390. doi:10.2307/3053285

Wilson, J. Q., \& Kelling, G. L. (1982). Broken Windows: The police and neighborhood safety. The Atlantic Monthly, March, 29-38.

Wing, C., Simon, K., \& Bello-Gomez, R. A. (2018). Designing Difference in Difference Studies: Best Practices for Public Health Policy Research. Annual Review of Public Health, 39(1), 453-469. doi:10.1146/annurev-publhealth-040617-013507

Wolfers, J. (2006). Did Unilateral Divorce Laws Raise Divorce Rates? A Reconciliation and New Results. American Economic Review, 96(5), 1802-1820. doi:10.1257/aer.96.5.1802

Wood, J. D., Sorg, E. T., Groff, E. R., Ratcliffe, J. H., \& Taylor, C. J. (2014). Cops as treatment providers: realities and ironies of police work in a foot patrol experiment. Policing and Society, 24(3), 362-379. doi:10.1080/10439463.2013.784292

Zimring, F. E. (2012). The City That Became Safe: New York's Lessons for Urban Crime and Its Control. New York: Oxford University Press.

Zimring, F. E., \& Hawkins, G. J. (1973). Deterrence: The Legal Threat in Crime Control. Chicago, IL: University of Chicago Press. 
Figure 1. Selected Precincts for the "Summer All Out" (SAO) Initiative on Crime and Violence

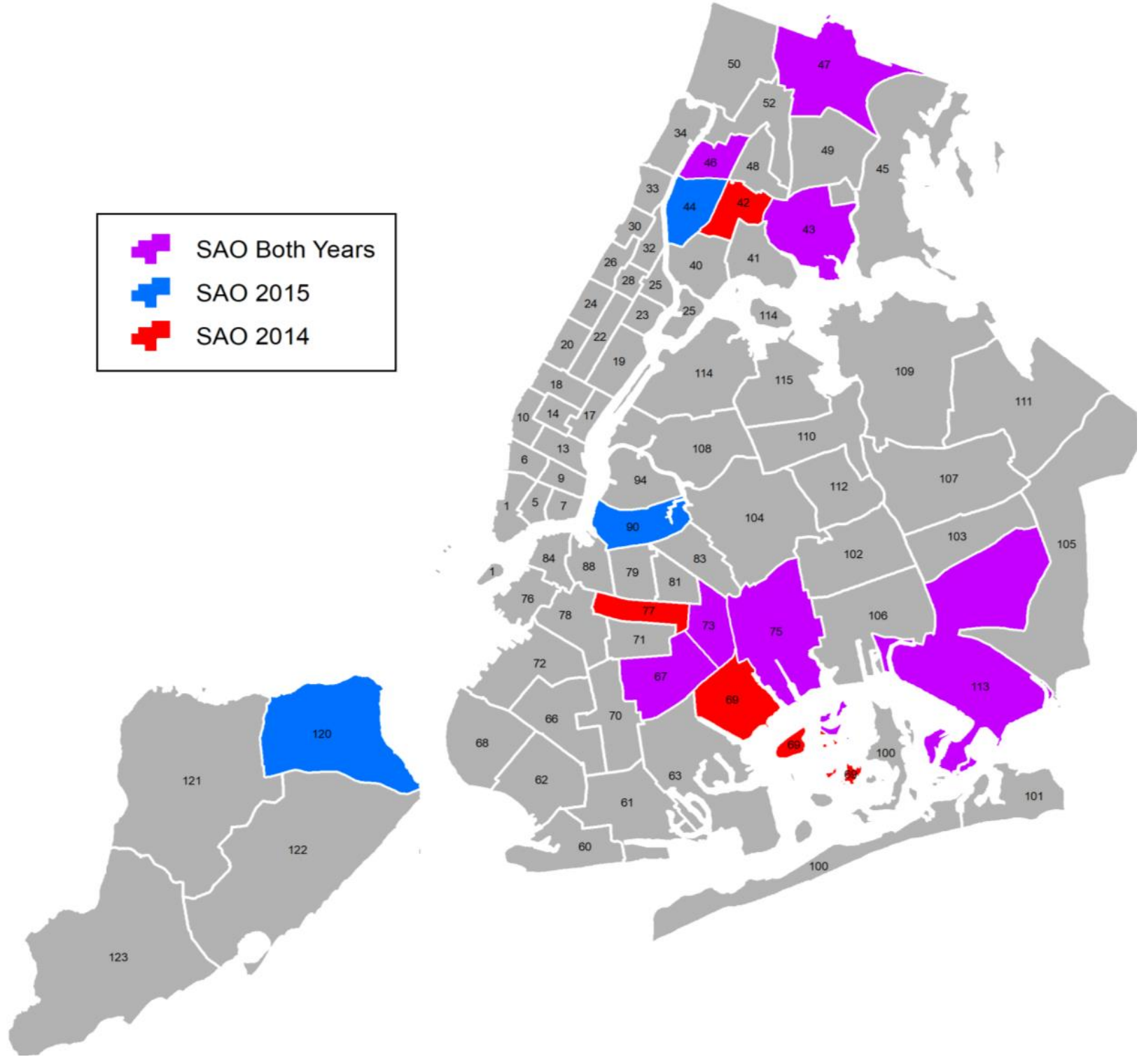


Figure 2. Aggregate Violent and Property Crime Trends, by SAO Adoption Year

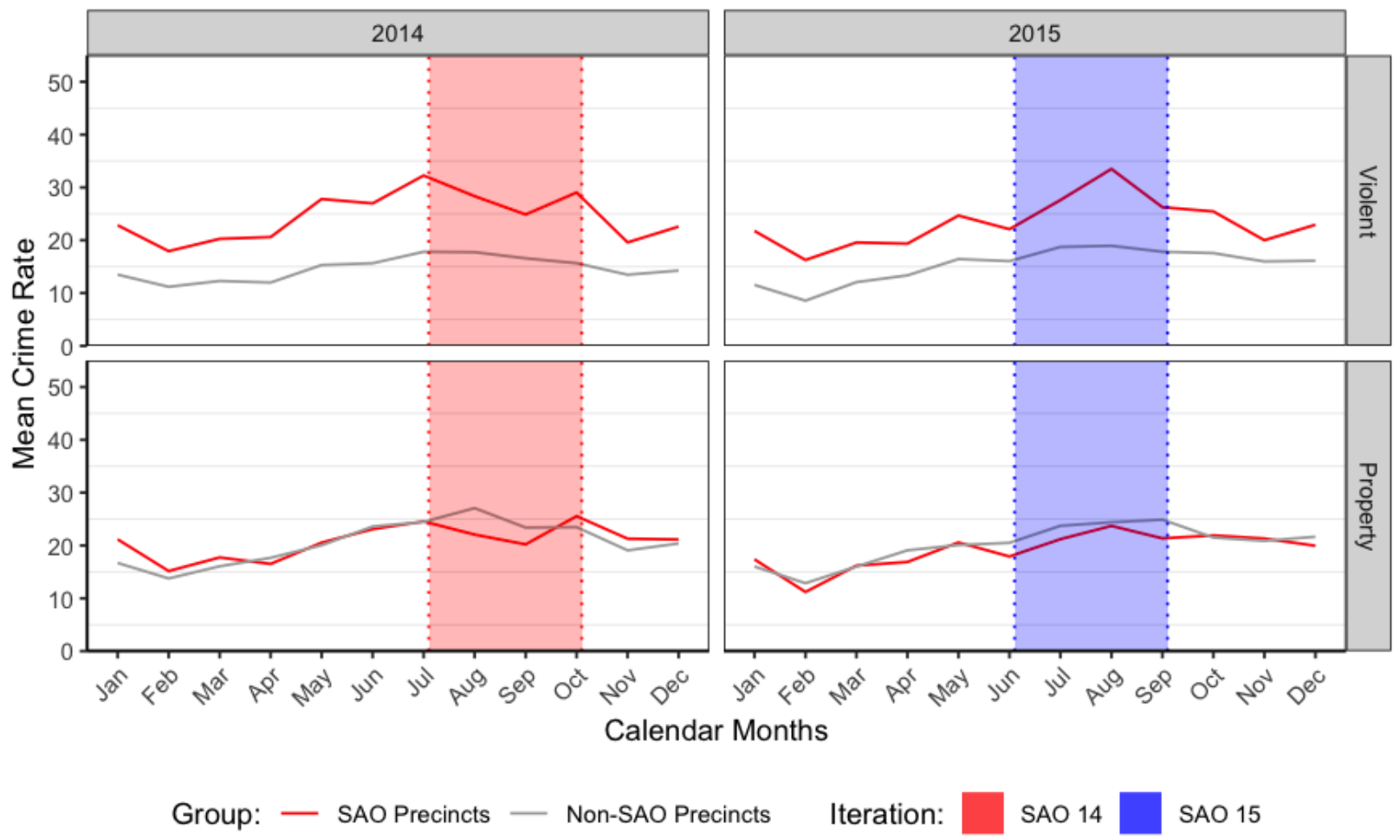


Figure 3. Dynamic Treatment Effects in 2014

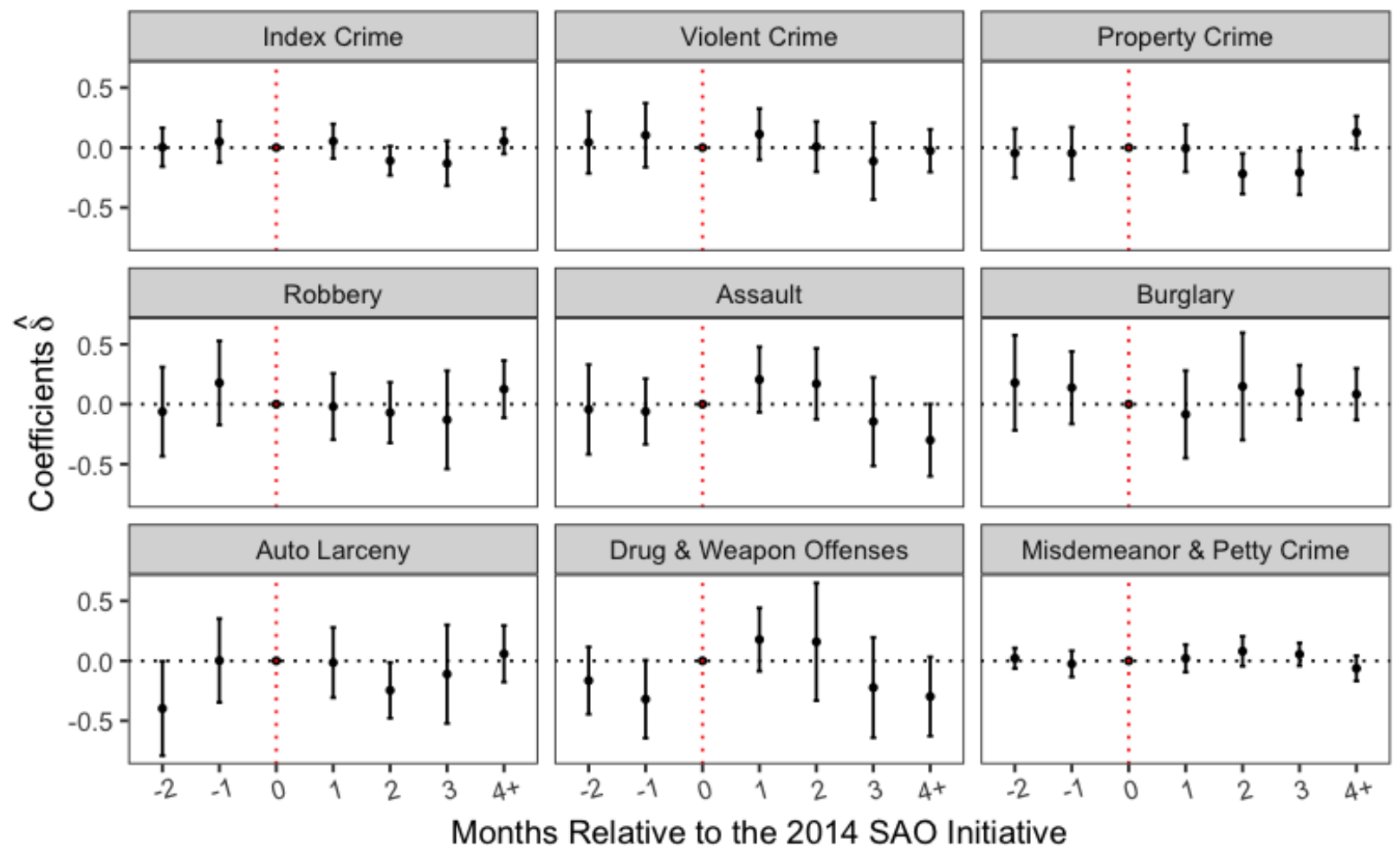


Figure 4. Dynamic Treatment Effects in 2015
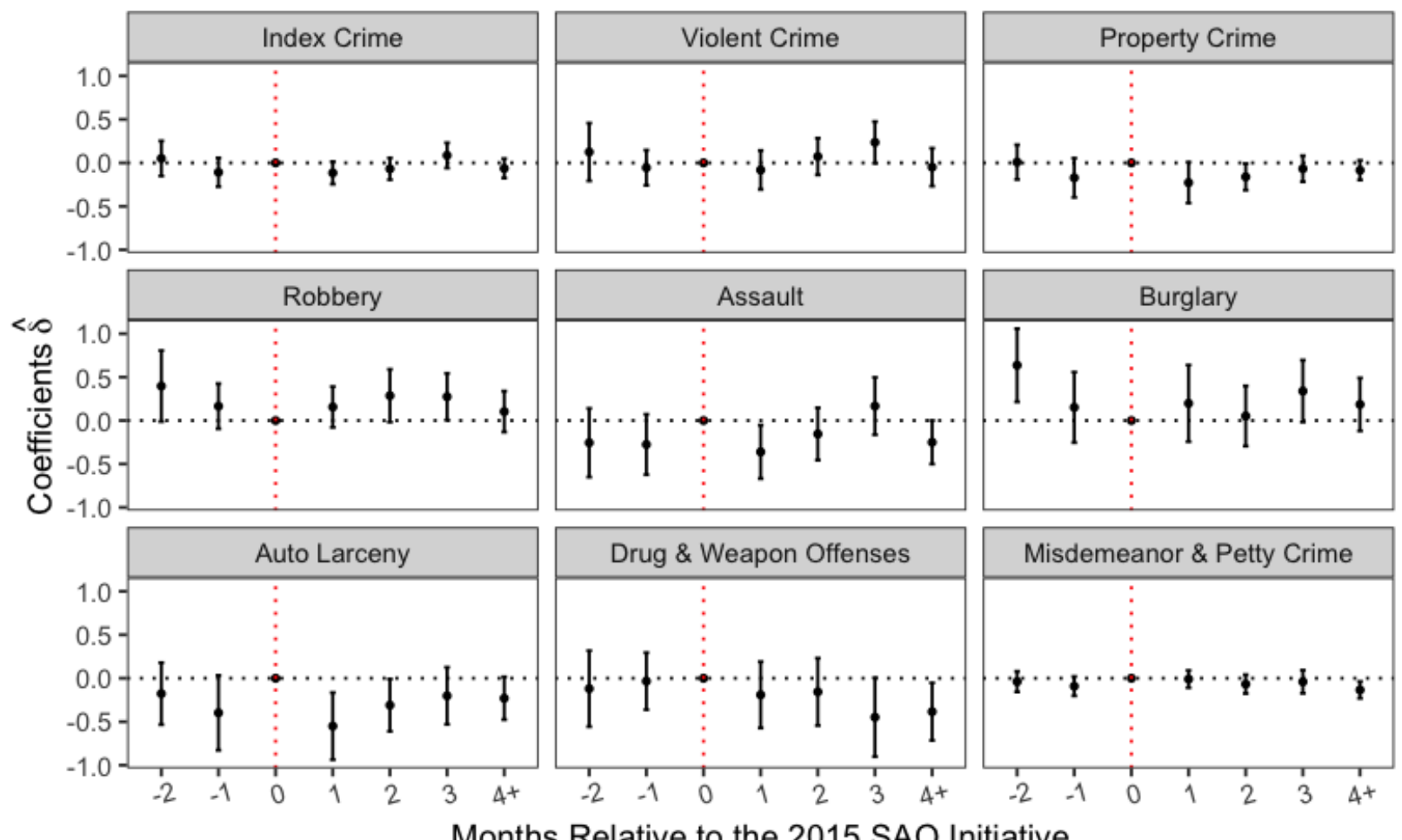

Months Relative to the 2015 SAO Initiative 
Table 1. Effect of the "Summer All Out" SAO Initiative on Crime

\begin{tabular}{|c|c|c|c|c|c|c|c|c|c|}
\hline & \multicolumn{9}{|c|}{ Logged Crime Rate per 100,000 Population } \\
\hline & $\begin{array}{l}\text { Index } \\
\text { Crime }\end{array}$ & $\begin{array}{l}\text { Violent } \\
\text { Crime }\end{array}$ & $\begin{array}{l}\text { Property } \\
\text { Crime }\end{array}$ & Robbery & Assault & Burglary ${ }^{\dagger}$ & $\begin{array}{c}\text { Auto } \\
\text { Larceny }\end{array}$ & $\begin{array}{l}\text { Weapon/ } \\
\text { Drug } \\
\text { Offenses }\end{array}$ & $\begin{array}{c}\text { Misdemeanor/ } \\
\text { Petty } \\
\text { Offenses }\end{array}$ \\
\hline \multicolumn{10}{|l|}{ Model 1} \\
\hline $2014\left(\hat{\delta}_{14}\right)$ & $\begin{array}{l}-0.11 \\
(0.06)\end{array}$ & $\begin{array}{l}-0.02 \\
(0.08)\end{array}$ & $\begin{array}{l}-0.18^{* *} \\
(0.07)\end{array}$ & $\begin{array}{l}-0.11 \\
(0.11)\end{array}$ & $\begin{array}{c}0.15 \\
(0.09)\end{array}$ & $\begin{array}{c}0.00 \\
(0.06)\end{array}$ & $\begin{array}{c}0.06 \\
(0.08)\end{array}$ & $\begin{array}{c}0.20 \\
(0.11)\end{array}$ & $\begin{array}{c}0.04 \\
(0.03)\end{array}$ \\
\hline $2015\left(\hat{\delta}_{15}\right)$ & $\begin{array}{l}-0.04 \\
(0.06)\end{array}$ & $\begin{array}{l}-0.03 \\
(0.06)\end{array}$ & $\begin{array}{l}-0.08 \\
(0.06)\end{array}$ & $\begin{array}{l}-0.04 \\
(0.08)\end{array}$ & $\begin{array}{c}0.03 \\
(0.10)\end{array}$ & $\begin{array}{c}0.06 \\
(0.09)\end{array}$ & $\begin{array}{l}-0.20 \\
(0.12)\end{array}$ & $\begin{array}{l}0.16^{*} \\
(0.08)\end{array}$ & $\begin{array}{r}0.03 \\
(0.04)\end{array}$ \\
\hline Model 2 & & & & & & & & & \\
\hline $1^{\text {st }}$ Lead $\left(\hat{\delta}_{+1}\right)$ & $\begin{array}{c}0.00 \\
(0.05)\end{array}$ & $\begin{array}{c}0.02 \\
(0.07)\end{array}$ & $\begin{array}{c}0.03 \\
(0.05)\end{array}$ & $\begin{array}{c}0.01 \\
(0.08)\end{array}$ & $\begin{array}{c}0.07 \\
(0.10)\end{array}$ & $\begin{array}{l}-0.02 \\
(0.05)\end{array}$ & $\begin{array}{l}0.05 \\
(0.10)\end{array}$ & $\begin{array}{l}0.25^{*} \\
(0.09)\end{array}$ & $\begin{array}{r}0.04 \\
(0.03)\end{array}$ \\
\hline SAO Dummy $\left(\hat{\delta}_{0}\right)$ & $\begin{array}{l}-0.02 \\
(0.06)\end{array}$ & $\begin{array}{c}0.03 \\
(0.08)\end{array}$ & $\begin{array}{l}-0.10^{*} \\
(0.05)\end{array}$ & $\begin{array}{l}-0.03 \\
(0.11)\end{array}$ & $\begin{array}{c}0.08 \\
(0.14)\end{array}$ & $\begin{array}{l}0.03 \\
(0.04)\end{array}$ & $\begin{array}{l}-0.10 \\
(0.11)\end{array}$ & $\begin{array}{l}-0.10 \\
(0.13)\end{array}$ & $\begin{array}{r}0.02 \\
(0.02)\end{array}$ \\
\hline $1^{\text {st }} \operatorname{Lag}\left(\hat{\delta}_{-1}\right)$ & $\begin{array}{l}-0.03 \\
(0.04)\end{array}$ & $\begin{array}{c}0.05 \\
(0.06)\end{array}$ & $\begin{array}{l}-0.09 \\
(0.05)\end{array}$ & $\begin{array}{c}0.09 \\
(0.09)\end{array}$ & $\begin{array}{c}0.00 \\
(0.15)\end{array}$ & $\begin{array}{c}0.02 \\
(0.03)\end{array}$ & $\begin{array}{l}-0.06 \\
(0.10)\end{array}$ & $\begin{array}{c}0.21 \\
(0.15)\end{array}$ & $\begin{array}{c}0.06 \\
(0.04)\end{array}$ \\
\hline $2^{\text {nd }} \operatorname{Lag}\left(\hat{\delta}_{-2}\right)$ & $\begin{array}{c}0.03 \\
(0.03)\end{array}$ & $\begin{array}{c}0.00 \\
(0.04)\end{array}$ & $\begin{array}{c}0.08 \\
(0.05)\end{array}$ & $\begin{array}{c}0.02 \\
(0.06)\end{array}$ & $\begin{array}{l}0.00 \\
(0.08)\end{array}$ & $\begin{array}{c}0.01 \\
(0.05)\end{array}$ & $\begin{array}{l}0.06 \\
(0.09)\end{array}$ & $\begin{array}{l}-0.20 \\
(0.10)\end{array}$ & $\begin{array}{l}-0.03 \\
(0.03)\end{array}$ \\
\hline
\end{tabular}

NOTES: $+=$ Non-street offenses. Model 1 reports coefficients from the classical DiD model. In 2014, 73 precincts were observed over 9 months for a total of 657 $(n * t)$ precinct-months. In 2015, 73 precincts were observed over 8 months for a total of $584(n * t)$ precinct-months. With the exception of burglary offenses, all crime indices restrict attention to "street" offenses. Model 2 reports coefficients from the "generalized" DiD equation which includes 73 precincts observed over 60 months for a total of 4,380 (n*t) precinct-month observations. Model 2 includes the SAO dummy which captures the immediate effect of the SAO initiative on crime in all month-years. Cluster robust standard errors reported in parentheses; Model 1 clusters on precinct; Model 2 clusters on precinct and month. Only the coefficients on policy variables in Model 2 are reported; dummies for precincts and months were excluded. 
Table 2. Year-Specific Poisson Estimates of the Effect of SAO Initiative on Shooting Incidents

\begin{tabular}{|c|c|c|c|c|c|c|}
\hline \multirow[b]{3}{*}{ Variables } & \multicolumn{6}{|c|}{ Shooting Incidents } \\
\hline & \multicolumn{3}{|c|}{2014} & \multicolumn{3}{|c|}{2015} \\
\hline & (1) & $(2)$ & (3) & (1) & $(2)$ & (3) \\
\hline \multirow[t]{2}{*}{$\hat{\delta}$ (Treat $\times$ Post $)$} & $-0.45 * *$ & $-0.45^{* *}$ & -0.46 & -0.25 & -0.25 & -0.03 \\
\hline & $(0.17)$ & $(0.15)$ & $(0.30)$ & $(0.18)$ & $(0.16)$ & $(0.20)$ \\
\hline \multicolumn{7}{|l|}{ Treat $\times$ SAO Months } \\
\hline \multirow[t]{2}{*}{ Treat $\times$ June } & & & & & & -0.28 \\
\hline & & & & & & $(0.32)$ \\
\hline \multirow[t]{2}{*}{ Treat $\times$ July } & & & -0.36 & & & -0.01 \\
\hline & & & $(0.33)$ & & & (0.29) \\
\hline \multirow[t]{2}{*}{ Treat $\times$ August } & & & -0.54 & & & 0.16 \\
\hline & & & $(0.31)$ & & & $(0.40)$ \\
\hline \multirow[t]{2}{*}{ Treat $\times$ September } & & & -0.47 & & & \\
\hline & & & $(0.30)$ & & & \\
\hline \multirow[t]{2}{*}{ Population/10,000 } & 0.02 & & & 0.02 & & \\
\hline & $(0.01)$ & & & $(0.01)$ & & \\
\hline \multirow[t]{2}{*}{ Land Area $\left(\right.$ Miles $^{2}$ ) } & $-0.04 * *$ & $-0.09 * *$ & $-0.09 *$ & $-0.04 *$ & $-0.09 * *$ & $-0.08 * *$ \\
\hline & $(0.02)$ & $(0.03)$ & $(0.03)$ & $(0.02)$ & $(0.03)$ & $(0.03)$ \\
\hline \multicolumn{7}{|l|}{ Adjustments } \\
\hline Exposure & No & Yes & Yes & No & Yes & Yes \\
\hline Clustered SEs & No & Yes & Yes & No & Yes & Yes \\
\hline Pre-Period Dummies & No & No & Yes & No & No & Yes \\
\hline \multicolumn{7}{|c|}{ 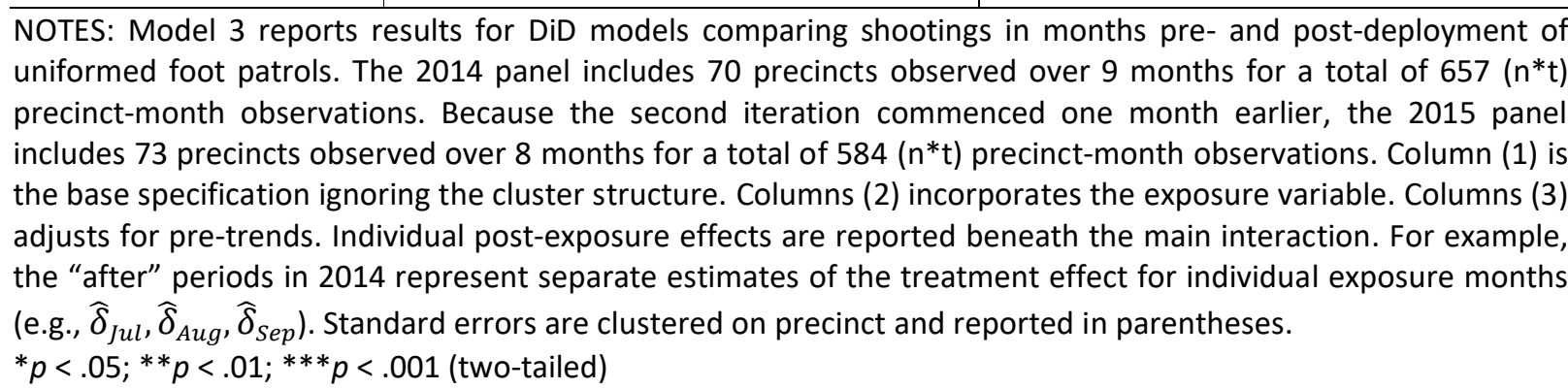 } \\
\hline
\end{tabular}




\section{Shooting Incidents}

(1)

\begin{tabular}{|c|c|c|c|c|c|}
\hline $1^{\text {st }}$ Lead $\left(\hat{\delta}_{+1}\right)$ & $\begin{array}{c}0.05 \\
(0.16)\end{array}$ & $\begin{array}{c}0.05 \\
(0.22)\end{array}$ & $\begin{array}{c}0.05 \\
(0.21)\end{array}$ & $\begin{array}{c}0.06 \\
(0.21)\end{array}$ & $\begin{array}{c}0.04 \\
(0.25)\end{array}$ \\
\hline SAO Dummy $\left(\hat{\delta}_{0}\right)$ & $\begin{array}{c}0.08 \\
(0.17)\end{array}$ & $\begin{array}{c}0.08 \\
(0.23)\end{array}$ & $\begin{array}{c}0.09 \\
(0.22)\end{array}$ & $\begin{array}{c}0.09 \\
(0.26)\end{array}$ & $\begin{array}{c}0.10 \\
(0.28)\end{array}$ \\
\hline $1^{\text {st }} \operatorname{Lag}\left(\hat{\delta}_{-1}\right)$ & $\begin{array}{c}-0.14 \\
(0.18)\end{array}$ & $\begin{array}{l}-0.14 \\
(0.18)\end{array}$ & $\begin{array}{c}-0.14 \\
(0.17)\end{array}$ & $\begin{array}{l}-0.13 \\
(0.22)\end{array}$ & $\begin{array}{l}-0.11 \\
(0.33)\end{array}$ \\
\hline $2^{\text {nd }} \operatorname{Lag}\left(\hat{\delta}_{-2}\right)$ & $\begin{array}{l}-0.07 \\
(0.17)\end{array}$ & $\begin{array}{l}-0.07 \\
(0.17)\end{array}$ & $\begin{array}{l}-0.07 \\
(0.17)\end{array}$ & $\begin{array}{l}-0.04 \\
(0.17)\end{array}$ & $\begin{array}{l}-0.14 \\
(0.24)\end{array}$ \\
\hline Neighbors & -- & -- & $\begin{array}{c}0.04 \\
(0.16)\end{array}$ & $\begin{array}{c}0.04 \\
(0.15)\end{array}$ & $\begin{array}{c}0.06 \\
(0.18)\end{array}$ \\
\hline Neighbors ( $1^{\text {st }}$ Lag) & -- & -- & $\begin{array}{c}0.02 \\
(0.18)\end{array}$ & $\begin{array}{c}0.03 \\
(0.17)\end{array}$ & $\begin{array}{c}0.05 \\
(0.20)\end{array}$ \\
\hline Clustered SEs (Precinct) & Yes & -- & -- & -- & -- \\
\hline Clustered SEs (Precinct \& Month) & No & Yes & Yes & Yes & Yes \\
\hline Precinct-Specific Linear Time Trends & No & No & No & Yes & Yes \\
\hline Precinct-Specific Quadratic Time Trends & No & No & No & No & Yes \\
\hline \multicolumn{6}{|c|}{$\begin{array}{l}\text { NOTES: The full panel includes } 70 \text { precincts observed over } 60 \text { months for a total of } 4,200(\mathrm{n} * \mathrm{t}) \text { precinct-month } \\
\text { observations. Monthly shooting incidents only include events occurring in open-air settings. Tabular results for } \\
\text { Model } 4 \text { exclude dummies for precincts and months. Columns (1) and (2) report alternative clustering schemes. } \\
\text { Column (3) incorporates a dummy for bordering precincts; the dummy was lagged to capture any delayed effects in } \\
\text { contiguous jurisdictions. Columns (4) and (5) stepwise include precinct-specific linear and quadratic time trends, } \\
\text { respectively. Cluster-robust standard errors are reported in parentheses. }\end{array}$} \\
\hline
\end{tabular}


Table 4. Poisson Estimates of SAO Initiative's Effects on Shooting Incidents, with Alternative Control Groups, 2012-2016

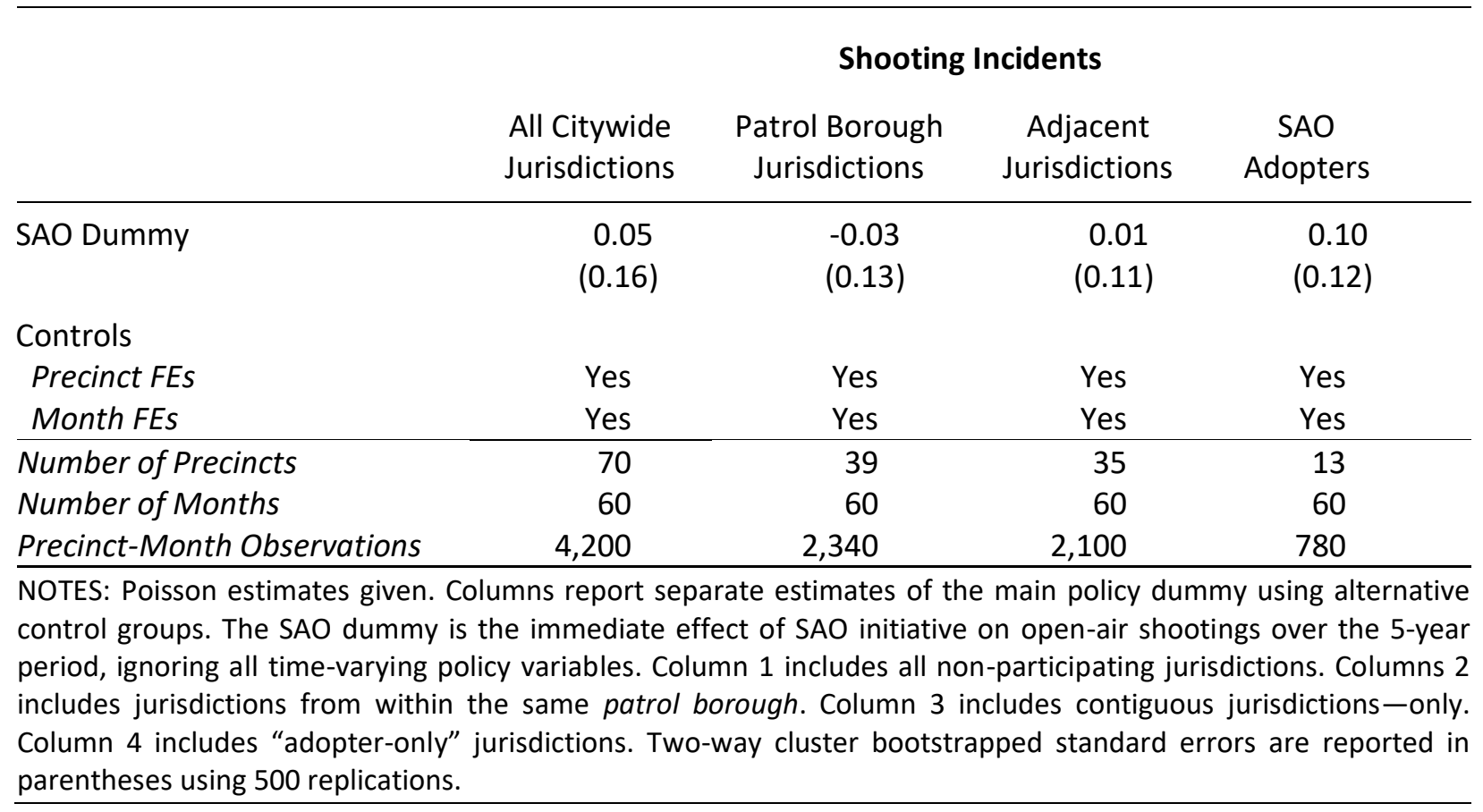


Table 5. Poisson Estimates of SAO Initiative's Effects on Shootings, Showing Heterogeneity by Day-ofWeek and Hour-of-Day, 2012-2016

\begin{tabular}{|c|c|c|c|c|}
\hline & \multicolumn{4}{|c|}{ Shooting Incidents } \\
\hline & \multicolumn{2}{|c|}{ Weekday/Weekend } & \multicolumn{2}{|c|}{ Day/Evening } \\
\hline & $\begin{array}{l}\text { Monday - } \\
\text { Thursday }\end{array}$ & $\begin{array}{l}\text { Friday - } \\
\text { Sunday }\end{array}$ & $\begin{array}{c}\text { Day } \\
\text { Shootings } \\
0400-1600\end{array}$ & $\begin{array}{c}\text { Night } \\
\text { Shootings } \\
1600-0400\end{array}$ \\
\hline SAO Dummy & $\begin{array}{c}0.06 \\
(0.20)\end{array}$ & $\begin{array}{l}-0.05 \\
(0.15)\end{array}$ & $\begin{array}{c}0.47 \\
(0.36)\end{array}$ & $\begin{array}{c}-0.11 \\
(0.10)\end{array}$ \\
\hline \multicolumn{5}{|l|}{ Controls } \\
\hline Precinct FEs & Yes & Yes & Yes & Yes \\
\hline Month FEs & Yes & Yes & Yes & Yes \\
\hline Number of Precincts & 70 & 70 & 70 & 70 \\
\hline Number of Months & 60 & 60 & 60 & 60 \\
\hline Precinct-Month Observations & 4,200 & 4,200 & 4,200 & 4,200 \\
\hline
\end{tabular}

NOTES: Each column is a separate estimation of Model 4 using only the SAO dummy and encompasses the full 60month observation period. The left two columns restrict attention to different subsets of the work week; Friday is included in the weekend estimate. The right two columns impose day and evening restrictions. Standard errors cluster on precinct and month. All models include a full set of precinct and month effects.

${ }^{*} p<.05 ;{ }^{* *} p<.01 ; * * * p<.001$ (two-tailed) 
Table 6. Dynamic Effects of SAO Initiative on Shooting Incidents, by Exposure Year

\begin{tabular}{|c|c|c|c|c|c|c|c|c|}
\hline \multirow[b]{3}{*}{ Variables } & \multicolumn{8}{|c|}{ Shooting Incidents } \\
\hline & \multicolumn{4}{|c|}{2014} & \multicolumn{4}{|c|}{2015} \\
\hline & (1) & $(2)$ & (3) & (4) & (1) & $(2)$ & (3) & (4) \\
\hline \multicolumn{9}{|l|}{ SAO Relative Effects } \\
\hline Month $t+3_{\text {backward }}$ & $\begin{array}{c}0.00 \\
(0.32)\end{array}$ & $\begin{array}{r}-0.35 \\
(0.38)\end{array}$ & $\begin{array}{l}-0.11 \\
(0.35)\end{array}$ & $\begin{array}{r}-0.59 \\
(0.40)\end{array}$ & $\begin{array}{r}0.19 \\
(0.24)\end{array}$ & $\begin{array}{r}0.03 \\
(0.30)\end{array}$ & $\begin{array}{c}0.54 \\
(0.37)\end{array}$ & $\begin{array}{c}0.25 \\
(0.60)\end{array}$ \\
\hline Month $t+2$ & $\begin{array}{l}-0.38 \\
(0.32)\end{array}$ & $\begin{array}{r}-0.54 \\
(0.34)\end{array}$ & $\begin{array}{l}-0.53 \\
(0.76)\end{array}$ & $\begin{array}{r}-0.74 \\
(0.59)\end{array}$ & $\begin{array}{r}0.00 \\
(0.45)\end{array}$ & $\begin{array}{r}-0.06 \\
(0.48)\end{array}$ & $\begin{array}{c}0.32 \\
(0.53)\end{array}$ & $\begin{array}{c}0.22 \\
(0.65)\end{array}$ \\
\hline Month $t+1$ & $\begin{array}{l}0.18 \\
(0.35)\end{array}$ & $\begin{array}{r}0.12 \\
(0.36)\end{array}$ & $\begin{array}{c}0.14 \\
(0.30)\end{array}$ & $\begin{array}{l}-0.25 \\
(0.39)\end{array}$ & $\begin{array}{r}0.78 \\
(0.44)\end{array}$ & $\begin{array}{r}0.78 \\
(0.41)\end{array}$ & $\begin{array}{c}0.62 \\
(0.49)\end{array}$ & $\begin{array}{c}0.28 \\
(0.92)\end{array}$ \\
\hline Month $t-1$ & $\begin{array}{l}-0.36 \\
(0.35)\end{array}$ & $\begin{array}{r}-0.23 \\
(0.33)\end{array}$ & $\begin{array}{l}-0.34 \\
(0.33)\end{array}$ & $\begin{array}{r}-0.58 \\
(0.43)\end{array}$ & $\begin{array}{r}-0.28 \\
(0.33)\end{array}$ & $\begin{array}{r}-0.16 \\
(0.29)\end{array}$ & $\begin{array}{l}-0.17 \\
(0.33)\end{array}$ & $\begin{array}{l}-0.10 \\
(0.40)\end{array}$ \\
\hline Month $t-2$ & $\begin{array}{l}-0.54 \\
(0.33)\end{array}$ & $\begin{array}{l}-0.31 \\
(0.32)\end{array}$ & $\begin{array}{l}-0.31 \\
(0.31)\end{array}$ & $\begin{array}{l}-0.25 \\
(0.48)\end{array}$ & $\begin{array}{r}-0.01 \\
(0.35)\end{array}$ & $\begin{array}{r}0.18 \\
(0.30)\end{array}$ & $\begin{array}{l}-0.02 \\
(0.31)\end{array}$ & $\begin{array}{l}-0.08 \\
(0.40)\end{array}$ \\
\hline Month $t-3$ & $\begin{array}{l}-0.47 \\
(0.33)\end{array}$ & $\begin{array}{r}-0.13 \\
(0.36)\end{array}$ & $\begin{array}{c}0.04 \\
(0.30)\end{array}$ & $\begin{array}{r}0.48 \\
(0.31)\end{array}$ & $\begin{array}{r}0.16 \\
(0.72)\end{array}$ & $\begin{array}{r}0.41 \\
(0.35)\end{array}$ & $\begin{array}{c}0.47 \\
(0.30)\end{array}$ & $\begin{array}{c}0.37 \\
(0.81)\end{array}$ \\
\hline Month $t-4_{\text {forward }}$ & $\begin{array}{c}-0.71^{* *} \\
(0.23)\end{array}$ & $\begin{array}{l}-0.26 \\
(0.27)\end{array}$ & $\begin{array}{l}-0.27 \\
(0.26)\end{array}$ & $\begin{array}{l}-0.22 \\
(0.39)\end{array}$ & $\begin{array}{r}-0.29 \\
(0.18)\end{array}$ & $\begin{array}{r}0.19 \\
(0.22)\end{array}$ & $\begin{array}{c}0.12 \\
(0.26)\end{array}$ & $\begin{array}{c}0.21 \\
(0.32)\end{array}$ \\
\hline \multicolumn{9}{|l|}{ Covariates / Adjustments } \\
\hline $\begin{array}{l}\text { Precinct } \times \text { Time Trends } \\
\text { Borough } \times \text { Month Dummies } \\
\text { Neighbors Dropped }\end{array}$ & $\begin{array}{l}\text { No } \\
\text { No } \\
\text { No }\end{array}$ & $\begin{array}{l}\text { Yes } \\
\text { No } \\
\text { No }\end{array}$ & $\begin{array}{l}\text { Yes } \\
\text { Yes } \\
\text { No }\end{array}$ & $\begin{array}{l}\text { Yes } \\
\text { Yes } \\
\text { Yes }\end{array}$ & $\begin{array}{l}\text { No } \\
\text { No } \\
\text { No }\end{array}$ & $\begin{array}{l}\text { Yes } \\
\text { No } \\
\text { No }\end{array}$ & $\begin{array}{l}\text { Yes } \\
\text { Yes } \\
\text { No }\end{array}$ & $\begin{array}{l}\text { Yes } \\
\text { Yes } \\
\text { Yes }\end{array}$ \\
\hline \multicolumn{9}{|c|}{$\begin{array}{l}\text { NOTES: Poisson estimates given. Tabular results report dynamic effects concentrating around each SAO exposure } \\
\text { phase. All models include a population offset and control for land area. Each model is restricted to a full calendar } \\
\text { year. Estimates } t_{+2}-t_{-3} \text { represent the interaction of a treatment indicator with a period (i.e., month) dummy } \\
\text { specific to SAO and non-SAO precincts; } t_{0} \text { is the period immediately before the intervention and is omitted as a } \\
\text { reference. Month } t+3_{\text {backward }} \text { is a dummy equal to unity in all months from period } 3 \text { before baseline going } \\
\text { backward. Month } t-4_{\text {forward }} \text { is a dummy equal to unity in period } 4 \text { after baseline going forward. Column (1) is the } \\
\text { base specification. Column (2) multiplies the treatment dummy by a continuous linear time index. Column (3) } \\
\text { includes a borough-by-month effect (i.e., Brooklyn-by-month and Bronx-by-month effect). Column (4) drops all } \\
\text { neighboring precincts to isolate experimental settings. To account for the reduction in available clusters and as an } \\
\text { additional robustness check, the standard errors were block (precinct) bootstrapped using } 500 \text { replications. } \\
{ }^{*} p<.05 ; * *<.01 ; * * * p<.001 \text { (two-tailed) }\end{array}$} \\
\hline
\end{tabular}

